NATIONAL LABORATORY

\title{
Alternate Methods for Eluting Cesium from Spherical Resorcinol-Formaldehyde Resin
}

\section{January 2009}

Prepared by

P. A. Taylor

H. L. Johnson

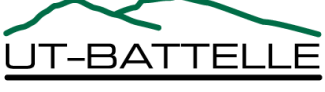




\section{DOCUMENT AVAILABILITY}

Reports produced after January 1, 1996, are generally available free via the U.S. Department of Energy (DOE) Information Bridge.

Web site http://www.osti.gov/bridge

Reports produced before January 1, 1996, may be purchased by members of the public from the following source.

National Technical Information Service

5285 Port Royal Road

Springfield, VA 22161

Telephone 703-605-6000 (1-800-553-6847)

TDD 703-487-4639

Fax 703-605-6900

E-mail info@ntis.fedworld.gov

Web site http://www.ntis.gov/support/ordernowabout.htm

Reports are available to DOE employees, DOE contractors, Energy Technology Data Exchange (ETDE) representatives, and International Nuclear Information System (INIS) representatives from the following source.

Office of Scientific and Technical Information

P.O. Box 62

Oak Ridge, TN 37831

Telephone 865-576-8401

Fax 865-576-5728

E-mail reports@osti.gov

Web site http://www.osti.gov/contact.html

This report was prepared as an account of work sponsored by an agency of the United States Government. Neither the United States government nor any agency thereof, nor any of their employees, makes any warranty, express or implied, or assumes any legal liability or responsibility for the accuracy, completeness, or usefulness of any information, apparatus, product, or process disclosed, or represents that its use would not infringe privately owned rights. Reference herein to any specific commercial product, process, or service by trade name, trademark, manufacturer, or otherwise, does not necessarily constitute or imply its endorsement, recommendation, or favoring by the United States Government or any agency thereof. The views and opinions of authors expressed herein do not necessarily state or reflect those of the United States Government or any agency thereof. 


\section{ALTERNATE METHODS FOR ELUTING CESIUM FROM SPHERICAL RESORCINOL-FORMALDEHYDE RESIN}

P. A. Taylor and H. L. Johnson

Date Published: January 2009

Prepared by

OAK RIDGE NATIONAL LABORATORY

P.O. Box 2008

Oak Ridge, Tennessee 37831-6283

managed by

UT-BATTELLE, LLC

for the

U.S. DEPARTMENT OF ENERGY

under contract DE-AC05-00OR22725 



\section{CONTENTS}

Page

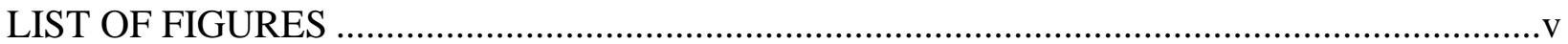

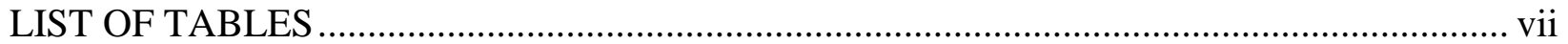

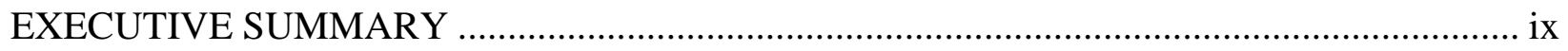

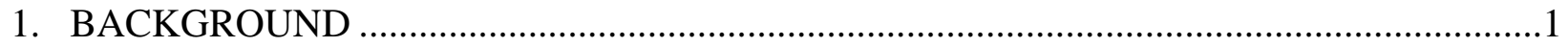

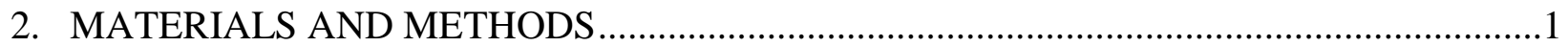

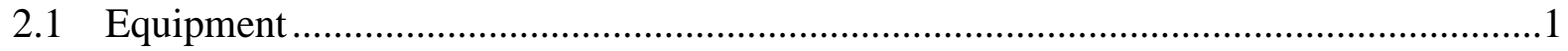

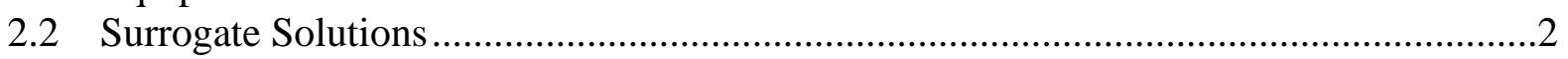

2.3 Spherical Resorcinol-Formaldehyde Resin ....................................................

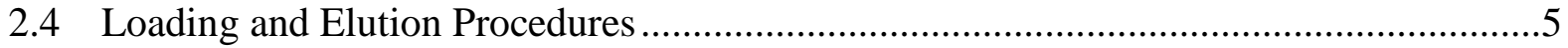

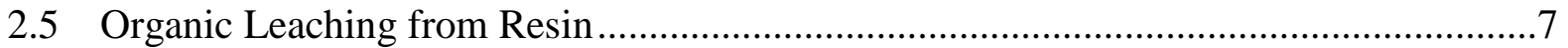

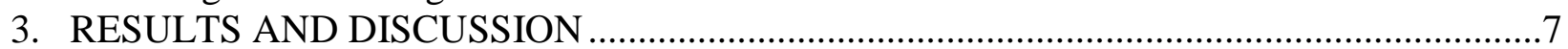

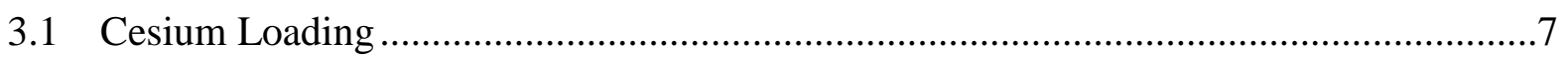

3.2 Cesium Elution..............................................................................................

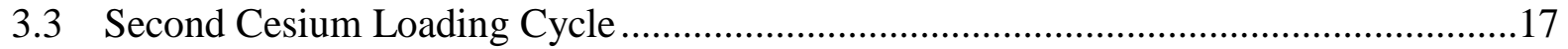

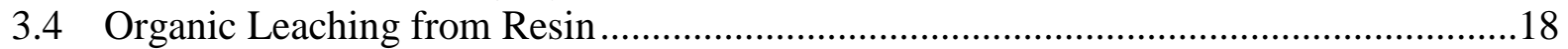

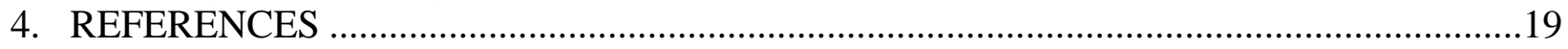

Appendix A SEMI-LOG PLOTS OF ELUTION RESULTS …........................................ A-1

Appendix B LISTING OF ANALYTICAL DATA FOR LOADING AND ELUTION

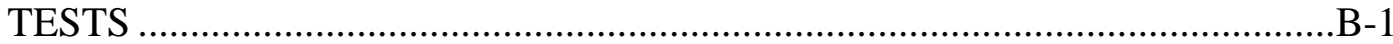

Appendix C VOLATILES ANALYSIS DETECTION LIMITS ….................................. 



\section{LIST OF FIGURES}

Figure

Page

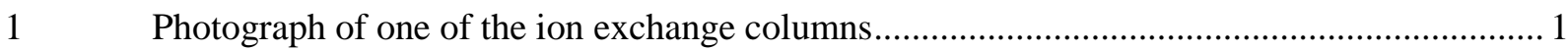

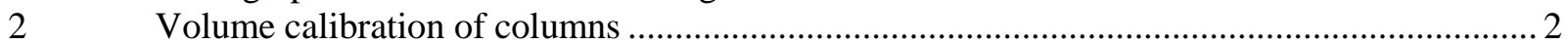

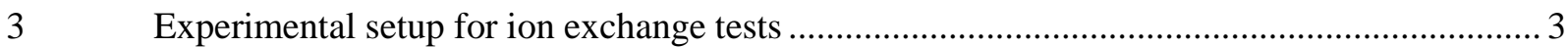

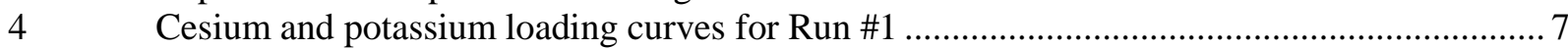

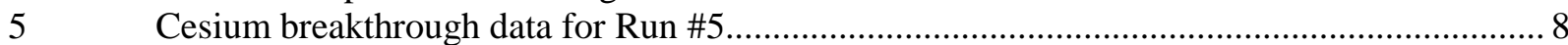

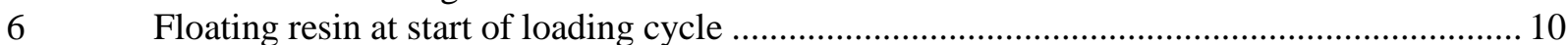

$7 \quad$ Results for baseline elution procedure (Runs \#2 and 5) ................................................ 10

8 Cesium results for elutions with lower concentrations of nitric acid (Runs \#2, 3, 9,

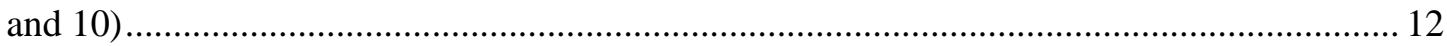

9 Results for elution with $0.5 \mathrm{MHNO}_{3}$, using alternate flow regimes (Runs \#1, 2, 4,

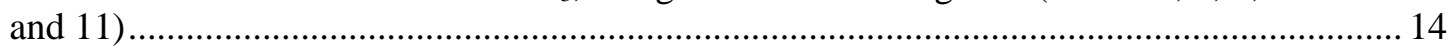

10 Results for elution with $0.5 \mathrm{M}$ formic acid solution (Runs \#7 and 17) ............................... 15

11 Results for elution with $0.8 \mathrm{M}$ boric acid solution (Run \#8) .......................................... 16

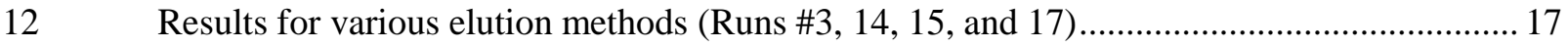

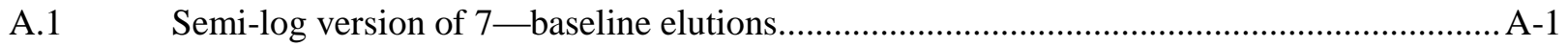

A.2 Semi-log version of 8 - alternate nitric acid concentrations ........................................... A-1

A.3 Semi-log version of 9-alternate flow regimes...............................................................

A.4 Semi-log version of Fig. 10 -formic acid elution........................................................... A-2 



\section{LIST OF TABLES}

\section{Table}

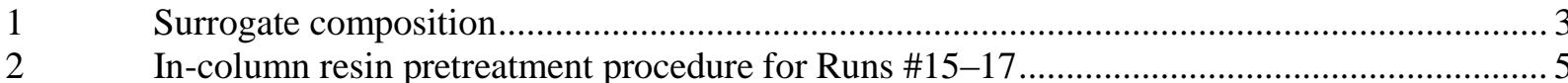

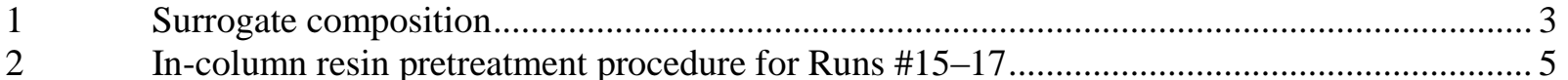

$3 \quad$ RF resin volume changes during pretreatment and use ..................................................

$4 \quad$ Cesium concentrations left on resin after elutions .......................................................... 16

$5 \quad$ Formaldehyde concentrations in solutions that were in contact with the RF resin ................ 18 



\section{EXECUTIVE SUMMARY}

A small-column ion exchange (SCIX) system has been proposed for removing cesium from the supernate and dissolved salt solutions in the high-level-waste tanks at the Savannah River Site (SRS). The SCIX system could use either crystalline silicotitanate (CST), an inorganic, nonregenerable sorbent, or spherical resorcinol-formaldehyde (RF), a new regenerable resin, to remove cesium from the waste solutions. The baseline method for eluting the cesium from the $\mathrm{RF}$ resin uses 15 bed volumes (BV) of $0.5 \mathrm{M}$ nitric acid $\left(\mathrm{HNO}_{3}\right)$. The nitric acid eluate, containing the radioactive cesium, would be combined with the sludge from the waste tanks and would be converted into glass at the Defense Waste Processing Facility (DWPF) at SRS. The amount of nitric acid that would be used to elute the RF resin, using the current elution protocol, exceeds the capacity of DWPF to destroy the nitrate ions and maintain the required chemical reducing environment in the glass melt. Installing a denitration evaporator at SRS is technically feasible but would add considerable cost to the project.

Alternate methods for eluting the resin have been tested, including using lower concentrations of nitric acid, other acids, and changing the flow regimes. About $4 \mathrm{BV}$ of $0.5 M \mathrm{HNO}_{3}$ are required to remove the sodium (titrate the resin) and most of the cesium from the resin, so the bulk of the acid used for the baseline elution method removes a very small quantity of cesium from the resin. A summary of the elution methods that have been tested is listed below.

Baseline elution $\left(0.5 \mathrm{MNO}_{3}\right.$ at $\left.1 \mathrm{BV} / \mathrm{hr}\right)$, for comparison

$0.5 \mathrm{MHNO}_{3}$ to titrate resin (at $1 \mathrm{BV} / \mathrm{hr}$ ), then either

- $0.05 M \mathrm{HNO}_{3}$ at $1 \mathrm{BV} / \mathrm{hr}$, or

- recirculate $0.5 \mathrm{M} \mathrm{HNO}_{3}$ at $1 \mathrm{BV} / \mathrm{hr}$, or

- staccato flow with $0.5 \mathrm{M} \mathrm{HNO}_{3}(1 \mathrm{BV} / \mathrm{hr}$ for $1 \mathrm{hr}$ then off for $3 \mathrm{hr}$ )

$0.5 \mathrm{M} \mathrm{HCOOH}$ (formic acid) at $1 \mathrm{BV} / \mathrm{hr}$

$0.8 M \mathrm{H}_{3} \mathrm{BO}_{3}$ (boric acid) at $1 \mathrm{BV} / \mathrm{hr}$

$0.2 \mathrm{M} \mathrm{HNO}_{3}$ at $1 \mathrm{BV} / \mathrm{hr}$

$0.1 \mathrm{M} \mathrm{HNO}_{3}$ at $1 \mathrm{BV} / \mathrm{hr}$

$0.5 \mathrm{MHN}_{3}$ at $0.56 \mathrm{BV} / \mathrm{hr}$

$0.5 \mathrm{M} \mathrm{HNO}_{3}$ at $2 \mathrm{BV} / \mathrm{hr}$

All of these lab-scale tests used a 1.5-cm-I.D. column, with a resin (sodium form) height of about $10 \mathrm{~cm}$, which is the same aspect ratio as the planned SCIX columns. Cesium was loaded on the resin using a surrogate salt solution, which represents the average dissolved salt composition at SRS, except that the cesium concentration was increased to $239 \mathrm{mg} / \mathrm{L}$. The resin was loaded with $9.5 \mathrm{~g} \mathrm{Cs} / \mathrm{L}$ of resin prior to elution, which is the maximum expected loading for RF resin treating the actual dissolved salt waste at SRS. With the higher cesium concentration surrogate, the loading required $20 \mathrm{hr}$, compared to about 10 days for the typical cesium concentration in the salt waste. One test used a surrogate with the typical $26 \mathrm{mg} \mathrm{Cs} / \mathrm{L}$ to load the resin, to determine if the longer contact time would affect the elution characteristics.

For the baseline elution method, $465 \mathrm{~g}$ of nitrate is used per liter of resin, and $>99.9999 \%$ of the cesium is removed from the resin. The alternative method that used $4 \mathrm{BV}$ of $0.5 M \mathrm{HNO}_{3}$ followed by $11 \mathrm{BV}$ of $0.05 \mathrm{M} \mathrm{HNO}_{3}$ used $158 \mathrm{~g}$ of nitrate per liter of resin (66\% less nitrate than 
that used for the baseline elution) and removed $>99.998 \%$ of the cesium. This elution procedure appears to be the most promising method tested for reducing the amount of nitric acid used while achieving very good cesium removal. Formic acid was slightly less efficient than nitric acid for eluting the resin, but $20 \mathrm{BV}$ of $0.5 \mathrm{M} \mathrm{HCOOH}$ removed $99.98 \%$ of the cesium from the resin. The Savannah River Site has not yet determined the amount of formic acid that can be accommodated at DWPF, but it is possible that a higher concentration of formic acid could be used to improve the elution and reduce the total volume of eluate. The resin that was loaded using the lower-cesium-concentration surrogate solution, with a total loading time of 13.5 days, was eluted using the baseline procedure and showed the same elution pattern as resin that was loaded in $20 \mathrm{hr}$ using the high-concentration surrogate. A staccato flow mode, using $0.5 \mathrm{M}$ $\mathrm{HNO}_{3}(1 \mathrm{hr}$ on at $1 \mathrm{BV} / \mathrm{hr}$, followed by $3 \mathrm{hr}$ off) after the resin had been titrated using a continuous flow of acid at $1 \mathrm{BV} / \mathrm{hr}$, removed $99.9998 \%$ of the cesium while using $12 \mathrm{BV}$ of acid (20\% less than the baseline).

For the last three tests, a second cesium-loading cycle was performed after elution, using either the baseline procedure, $0.05 M \mathrm{HNO}_{3}$ following the initial titration by $0.5 M \mathrm{HNO}_{3}$, or $0.5 M$ formic acid. The goal of these tests was to measure any impact of the first elution on the initial phase of the next loading cycle. The second loading cycle used a surrogate salt solution containing $55 \mathrm{mg} / \mathrm{L} \mathrm{Cs}$. Direct measurement of the surrogate effluent samples using the most sensitive method available gave non-detects for the cesium concentration in all of the samples from these runs. The detection limit for these samples is mostly driven by the high sodium concentration $(\sim 6 M)$ in the surrogate solution. In order to improve the detection limit for cesium, a secondary extraction and elution procedure was performed on three composite effluent samples (early, middle, and late) from each run. This treatment approximately doubled the cesium concentration from the surrogate effluent samples and greatly reduced the sodium concentration. The cesium concentrations in the surrogate effluent composites averaged $4.2 \mu \mathrm{g} / \mathrm{L}$ for the baseline elution, $4.1 \mu \mathrm{g} / \mathrm{L}$ for the $0.05 M \mathrm{HNO}_{3}$ elution, and $18.5 \mu \mathrm{g} / \mathrm{L}$ for the formic acid elution, with no systematic trend for the early, middle, and late samples. These results showed that the two elution procedures using nitric acid produced equivalent results, while the formic acid procedure caused a statistically significant increase in the cesium effluent concentration during the initial phase of the next loading cycle, although the concentration was still quite low.

Samples of the various solutions that had been in contact with the resin were analyzed for formaldehyde (EPA Method 8315A) and volatile organic compounds (EPA Method 8260B). The solutions sampled included the water that the resin had been stored in since being manufactured, the surrogate dissolved salt solution, $0.5 M \mathrm{HNO}_{3}, 0.25 M \mathrm{NaOH}$, and $0.5 M$ formic acid. The water that the resin had been stored in since 2005 contained the highest concentration of formaldehyde $(13.3 \mathrm{mg} / \mathrm{L})$. The $\mathrm{NaOH}$ solution contained $4.67 \mathrm{mg} / \mathrm{L}$, the $\mathrm{HNO}_{3}$ contained $1.33 \mathrm{mg} / \mathrm{L}$, and the formic acid contained $1.80 \mathrm{mg} / \mathrm{L}$. The dissolved salt surrogate solution contained less than the detection limit of $0.05 \mathrm{mg} / \mathrm{L}$ of formaldehyde. No other volatile organic compounds (VOC) were detected in any of the samples. The detection limit for the 64 compounds listed on the VOC report ranged from 0.001 to $0.05 \mathrm{mg} / \mathrm{L}$. 


\section{BACKGROUND}

A small-column ion exchange (SCIX) system has been proposed for removing cesium from the supernate and dissolved salt solutions in the high-level-waste tanks at the Savannah River Site (SRS). The SCIX system could use either crystalline silicotitanate (CST), an inorganic, nonregenerable sorbent, or spherical resorcinol-formaldehyde (RF), a new regenerable resin, to remove cesium from the waste solutions. The RF resin has been studied extensively for possible use at the Hanford Site, ${ }^{1}$ and more recently for use at SRS. ${ }^{2}$ The baseline method for eluting the cesium from the RF resin involves 15 bed volumes (BV) of $0.5 \mathrm{M}$ nitric acid $\left(\mathrm{HNO}_{3}\right)$. The nitric acid eluate, containing the radioactive cesium, would be combined with the sludge from the waste tanks and would be converted into glass at the Defense Waste Processing Facility (DWPF) at SRS. The amount of nitric acid that would be used to elute the RF resin, using the current elution protocol, exceeds the capacity of DWPF to destroy the nitrate ions and maintain the required chemical reducing environment in the glass melt. Installing a denitration evaporator at SRS is technically feasible but would add considerable cost to the project. This work examined methods to elute the RF resin while using lower amounts of nitric acid or alternate acids.

\section{MATERIALS AND METHODS}

\section{$2.1 \quad$ Equipment}

Either of two small columns, fabricated from 0.5-in. clear polyvinyl chloride (PVC) pipe, with glued threaded end adapters, was used as the ion exchange column for these tests (Fig. 1). The stainless steel end caps have a 100-mesh stainless steel screen tack-welded inside to retain the ion exchange resin and 1/16-in. stainless steel tubing for inlet and outlet flow. The inner diameter of the columns was determined by measuring the height of aliquots of water added to the column. The results are shown in Fig. 2, and the calculated I.D. is $1.51 \mathrm{~cm}$ for each column. The total volume of the columns is $36 \mathrm{~mL}$.

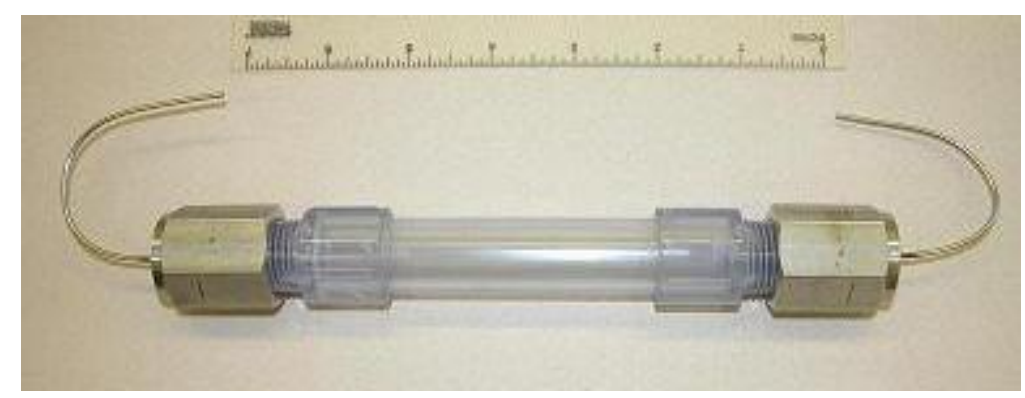

Fig. 1. Photograph of one of the ion exchange columns. 


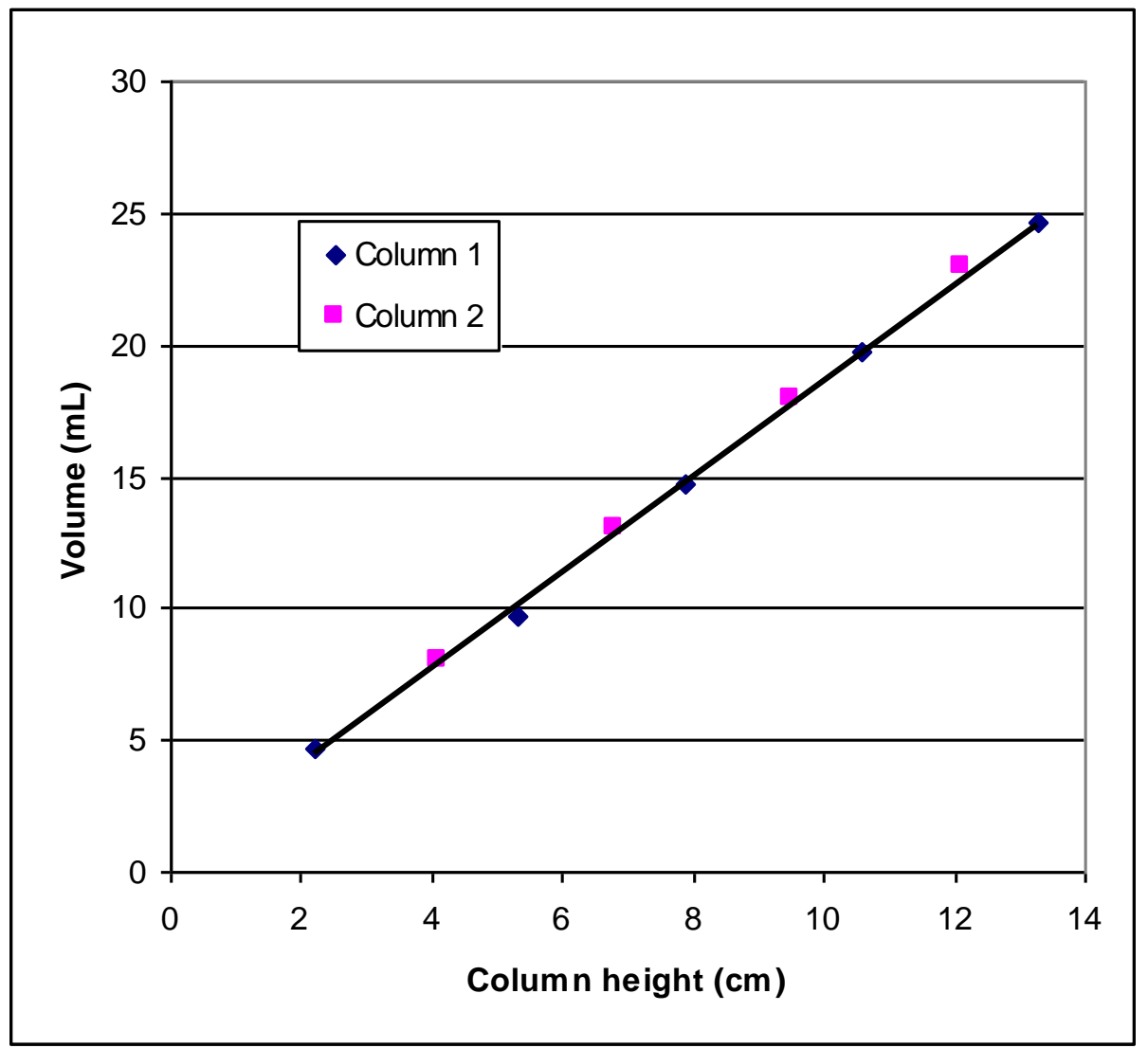

Fig. 2. Volume calibration of columns.

A Masterflex (Cole-Parmer Instrument Company, Vernon Hills, IL) peristaltic pump and 1/32-in.-I.D. PharMed (Saint-Gobain Performance Plastics, Corp., Granville, NY) tubing were used to pump solutions through the columns. The effluent from the columns was collected in $50 \mathrm{~mL}$ polypropylene centrifuge tubes, using a Spectra/Chrom CF-1 (Spectrum, Houston, TX) fraction collector to automatically advance the centrifuge tubes at timed intervals. Figure 3 shows a photograph of the pump, column, and fraction collector. A Mettler AE163 analytical balance (Mettler-Toledo, Inc., Columbus, $\mathrm{OH}$ ) was used to weigh chemicals and resin samples.

\subsection{Surrogate Solutions}

The dissolved salt surrogate used for loading cesium on the RF resin was based on the average predicted dissolved salt concentration for all of the SRS tanks. The recipe was previously developed by Doug Walker at the Savannah River National Laboratory (SRNL) (personal communication, Doug Walker to Paul Taylor). The cesium concentration was increased to $0.0018 M(239 \mathrm{mg} / \mathrm{L})$ for most of the surrogate solutions to reduce the time required for loading the resin. Reagent-grade chemicals were used to prepare the surrogate. Some precipitate was formed during formulation of the surrogate and was removed by filtration prior to use. 


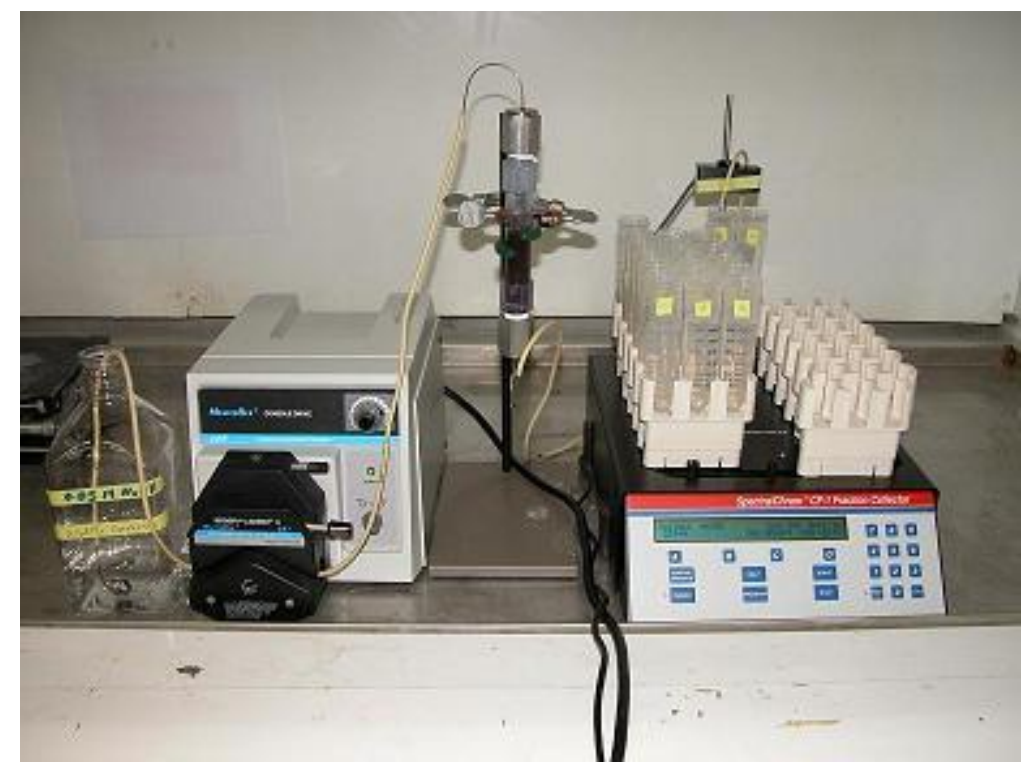

Fig. 3. Experimental setup for ion exchange tests.

The surrogate solution was analyzed at the ORNL Radioactive Materials Analytical Laboratory (RMAL) by inductively coupled plasma-mass spectroscopy (ICP-MS) for metals and ion chromatography (IC) for anions (Table 1). The analytical results show that part of the phosphate and fluoride did not remain dissolved. The detection limit for silicon was higher than the concentration that was added, so it is not known how much stayed in solution. Phosphate, fluoride, and silicate are minor components of the surrogate and are not known to affect cesium loading on the RF resin, so the impact of the change in surrogate concentration caused by the precipitation on the cesium elution results should be insignificant. The total measured sodium concentration was $6.2 \mathrm{M}$.

Table 1. Surrogate composition

\begin{tabular}{|c|c|c|}
\hline \multirow{2}{*}{ Component } & \multicolumn{2}{|c|}{ Concentration $(M)$} \\
\hline & Target & Measured \\
\hline $\mathrm{NaOH}$ & 1.1 & $\mathrm{NA}^{a}$ \\
\hline $\mathrm{NaNO}_{3}$ & 2.4 & 2.4 as $\mathrm{NO}_{3}$ \\
\hline $\mathrm{NaNO}_{2}$ & 0.34 & 0.34 as $\mathrm{NO}_{2}$ \\
\hline $\mathrm{Al}\left(\mathrm{NO}_{3}\right)_{3}$ & 0.54 & 0.55 as $\mathrm{Al}$ \\
\hline $\mathrm{Na}_{2} \mathrm{SO}_{4}$ & 0.30 & 0.30 as $\mathrm{SO}_{4}$ \\
\hline $\mathrm{Na}_{2} \mathrm{CO}_{3}$ & 0.55 & NA \\
\hline $\mathrm{NaCl}$ & 0.035 & 0.035 as $\mathrm{Cl}$ \\
\hline $\mathrm{NaF}$ & 0.033 & 0.006 as $\mathrm{F}$ \\
\hline $\mathrm{Na}_{2} \mathrm{HPO}_{4}$ & 0.13 & 0.02 as $\mathrm{PO}_{4}$ \\
\hline $\mathrm{Na}_{2} \mathrm{SiO}_{3}$ & 0.005 & $<0.01$ as $\mathrm{Si}$ \\
\hline $\mathrm{KNO}_{3}$ & 0.006 & 0.006 as $\mathrm{K}$ \\
\hline $\mathrm{CsCl}$ & 0.0018 & 0.0018 as $\mathrm{Cs}$ \\
\hline
\end{tabular}

${ }^{a} \mathrm{NA}=$ not analyzed 


\subsection{Spherical Resorcinol-Formaldehyde Resin}

The spherical resorcinol-formaldehyde (RF) resin used in these tests was obtained from Microbeads (Skedsmokorset, Norway), Lot Number 5E-370/641, which was produced on $5 / 24 / 2005$ in a 50-gal production batch. The resin was stored in water, in the hydrogen form, in 1-L glass bottles. The bottle of resin used for these tests was delivered to ORNL from SRS on 6/23/2008.

For the first 14 column tests, the resin was weighed in the hydrogen form prior to being added to the column. A sample of the resin was dewatered on a filter paper, under vacuum, and then weighed. Damp resin was transferred into a graduated cylinder containing deionized water to give an average resin volume of $14.5 \mathrm{cc}$. The remaining resin was weighed to determine the weight of damp resin that had been added to the graduated cylinder. A second aliquot of damp resin was weighed, air dried overnight, and reweighed to determine the moisture content. The moisture content was used to calculate the dry weight of the resin placed in the column, which averaged $7.2 \mathrm{~g}$ of hydrogen-form resin, giving a bulk density of $0.50 \mathrm{~g} / \mathrm{cc}$ for the as-received resin. For the first test, the resin was dried on a plastic weighing dish, and as the resin dried, there was enough static charge developed that a few of the resin beads jumped out of the dish. All of the other tests used a glass beaker to dry the resin. The resin from the graduated cylinder was sluiced into the column and was then regenerated to the sodium form by pumping $120 \mathrm{~mL}$ (6 BV) of $0.25 \mathrm{M} \mathrm{NaOH}$ up through the column at a flow rate of $0.6 \mathrm{~mL} / \mathrm{min}(2 \mathrm{BV} / \mathrm{hr}$ ). (Note that all of the bed volume numbers used in this report are referenced to the resin volume calculated from the measured resin bed height in the column after regeneration to the sodium form.) The resin was then ready for loading with cesium, using the surrogate solution described above. The resin volume after regeneration averaged $20.3 \mathrm{cc}$, a $40 \%$ expansion from the hydrogen form that was originally added to the column, which is similar to that measured at Hanford $^{3}$ (33\% to $47 \%$ ) for the first conversion from the as-received hydrogen form to the sodium form. After the elution step, when the resin was back in the hydrogen form, the average volume was $17.9 \mathrm{cc}$, a $24 \%$ increase compared to the original hydrogen-form volume, which is similar to previous results at Hanford. The first cycle from hydrogen form to sodium form and then back to hydrogen form causes a permanent expansion of the resin, called "relaxing" the resin. Subsequent cycles do not change the resin volume significantly.

For the last three column tests, the resin was converted to the sodium form in a batch mode by adding $5 \mathrm{BV}$ of $1 \mathrm{M} \mathrm{NaOH}$ to the resin, mixing gently every $10 \mathrm{~min}$ for $30 \mathrm{~min}$, and then letting

it set overnight. The air in the headspace of the bottle containing the resin and sodium hydroxide was displaced with argon, to reduce the potential for oxidizing the resin. A 20.0-cc portion of the resin was measured in a graduated cylinder and added to the column. The volume of the remaining resin was measured, dewatered by filtration, air dried, and weighed. The weight-tovolume ratio of the resin sample was used to calculate the dry weight of resin in the column, which averaged $9.4 \mathrm{~g}$ for $20.0 \mathrm{cc}$ of the sodium-form resin, giving a bulk density of $0.47 \mathrm{~g} / \mathrm{cc}$. The resin in the column was further pretreated as described in Table 2, which follows a procedure developed at Hanford ${ }^{1}$ and SRS. ${ }^{2}$ All of the solutions used in pretreating the resin were pumped up through the resin bed. The initial volume of the sodium-form resin $(20 \mathrm{cc})$ was used as the bed volume measurement for all of the steps. The resin was ready for the cesiumloading step after completing the sequence described in Table 2. 
Table 2. In-column resin pretreatment procedure for Runs \#15-17

\begin{tabular}{lll}
\hline \multicolumn{1}{c}{ Sequence of solutions } & \multicolumn{1}{c}{ Volume } & \multicolumn{1}{c}{ Flow rate } \\
\hline 1. Deionized water & 3 column volumes $(108 \mathrm{~mL})$ & $3 \mathrm{BV} / \mathrm{hr}(1.0 \mathrm{~mL} / \mathrm{min})$ \\
2. $0.5 \mathrm{M} \mathrm{HNO}_{3}$ & 8 bed volumes $(160 \mathrm{~mL})$ & $3 \mathrm{BV} / \mathrm{hr}$ \\
3. Deionized water & 3 column volumes $(60 \mathrm{~mL})$ & $1.4 \mathrm{BV} / \mathrm{hr}(0.47 \mathrm{~mL} / \mathrm{min})$ \\
4. $0.5 \mathrm{M} \mathrm{NaOH}$ & 6 bed volumes $(120 \mathrm{~mL})$ & $3 \mathrm{BV} / \mathrm{hr}$ \\
\hline
\end{tabular}

Table 3 shows the average resin volume, and standard deviation, for each step in the pretreatment process and during the cesium loading and elution steps for the last three runs (15-17). The volumes were calculated from the measured height of the resin bed in the column. The initial resin volume, as measured in a graduated cylinder, prior to loading the resin in the column, was $20.0 \mathrm{cc}$. The results in the "\% Change" column are all calculated from this original volume. Sluicing the resin into the column slightly expanded the resin volume. Converting the resin to the hydrogen form, either during the pretreatment process or during the first cesiumelution step, reduced the volume of the resin by over 19\%, compared to the initial sodium-form volume; however, the second time the resin was eluted, the volume reduction was lower $(17.6 \%$ less than the initial volume). All of the elution and loading solutions were pumped down through the resin bed, but the $0.5 \mathrm{M} \mathrm{NaOH}$ solutions used to regenerate the resin were pumped upflow.

Table 3. RF resin volume changes during pretreatment and use

\begin{tabular}{lcrr}
\hline \multicolumn{1}{c}{ Treatment step } & $\begin{array}{c}\text { Volume } \\
\text { (cc) }\end{array}$ & \multicolumn{1}{c}{$\begin{array}{c}\text { Std. dev. } \\
\text { (cc) }\end{array}$} & \% Change \\
\hline Resin (sodium form) added to column & 20.1 & 0.21 & $0.63 \%$ \\
After conversion to hydrogen form with $0.5 \mathrm{M} \mathrm{HNO}_{3}$ & 16.2 & 0.19 & $-19.17 \%$ \\
After upflow regeneration to sodium form with $0.5 \mathrm{M} \mathrm{NaOH}$ & 20.2 & 0.15 & $0.92 \%$ \\
After first loading step with surrogate & 20.1 & 0.17 & $0.33 \%$ \\
After displacement with $0.5 \mathrm{M} \mathrm{NaOH}$ & 20.3 & 0.17 & $1.39 \%$ \\
After elution with 0.5 $M \mathrm{HNO}_{3}$ & 16.1 & 0.10 & $-19.51 \%$ \\
After upflow regeneration to sodium form with $0.5 \mathrm{M} \mathrm{NaOH}$ & 20.0 & 0.18 & $-0.15 \%$ \\
After second loading step with surrogate & 20.1 & 0.16 & $0.50 \%$ \\
After displacement with $0.5 \mathrm{M} \mathrm{NaOH}^{\prime}$ & 20.4 & 0.10 & $1.98 \%$ \\
After elution with $0.5 \mathrm{HNO}_{3}$ & 16.5 & 0.22 & $-17.61 \%$ \\
\hline
\end{tabular}

The height of the sodium-form resin in the column was about $10 \mathrm{~cm}$, which gives an aspect ratio of $6.7 \mathrm{in}$. the $1.5-\mathrm{cm}-\mathrm{ID}$ column, which is the same as that proposed for the ion exchange columns in the SCIX system.

\subsection{Loading and Elution Procedures}

Previous modeling work at SRS ${ }^{4}$ using a Frenundlich/Langmuir isotherm, had predicted maximum cesium loadings of 1.05 to $9.5 \mathrm{~g} \mathrm{Cs} / \mathrm{L}$ of resin for $\mathrm{RF}$ resin that would be used to treat the dissolved salt waste from tanks 1, 2, 3, 37, and 41, while producing decontaminated salt solution that would meet the waste acceptance criteria for the Saltstone Facility. The cesium loading procedure used for these tests was designed to load $9.5 \mathrm{~g} \mathrm{Cs} / \mathrm{L}$ resin in about $20 \mathrm{hr}$. The 
surrogate described above contains $239 \mathrm{mg} / \mathrm{L}$ of cesium. This surrogate was pumped down through the column containing the $\mathrm{RF}$ resin at a flow rate of $0.6 \mathrm{~mL} / \mathrm{min}(2 \mathrm{BV} / \mathrm{hr})$ until $720 \mathrm{~mL}$ (36 BV) of surrogate had passed through the column. For the first two tests, the surrogate effluent was collected in $\sim 30$-mL portions using the fraction collector, and selected samples were analyzed for cesium and potassium. For subsequent tests, the effluent was collected as one sample in a graduated cylinder, and only one sample was analyzed. Run \#5 used a lower concentration cesium (26-48 mg/L) surrogate during the loading phase. The loading phase for this test lasted 13.5 days, and $9075 \mathrm{~mL}$ (454 BV) of surrogate was pumped through the resin. The cumulative time that surrogate was being actively pumped through the column was 10.5 days, but the tubing plugged several times during this run by solids that had precipitated in the surrogate, which extended the time that the resin was in contact with the surrogate. Batches of the Run \#5 effluent were periodically collected, sampled for analysis of cesium and potassium, and recycled by adding $26 \mathrm{mg} / \mathrm{L}$ of cesium and returning the solution to the feed bottle. This test was designed to determine if the longer contact time with the surrogate would affect the cesium elution.

For all of the tests, after the loading phase was completed, the surrogate was displaced using $3 \mathrm{BV}$ of $0.25 \mathrm{M} \mathrm{NaOH}$ at $2 \mathrm{BV} / \mathrm{hr}$, and then the caustic was displaced by $3 \mathrm{BV}$ of deionized water at $2 \mathrm{BV} / \mathrm{hr}$. The resin was then ready for elution.

A summary of the various elution procedures that were tested is listed below. A total of 17 loading and elution tests were performed. The elutions were typically run for $15 \mathrm{hr}$, except for the boric acid and first formic acid elutions which were run for $20 \mathrm{hr}$.

Baseline elution (15 BV of $0.5 M \mathrm{HNO}_{3}$ at $1 \mathrm{BV} / \mathrm{hr}$ ), for comparison (Runs \#2, 5, 12, and 15)

$0.5 \mathrm{MHNO}_{3}$ to titrate resin (at $1 \mathrm{BV} / \mathrm{hr}$ ), then either

$-0.05 \mathrm{M} \mathrm{HNO}_{3}$ at $1 \mathrm{BV} / \mathrm{hr}$ (Runs \#3, 13, and 16), or

-recirculate $0.5 \mathrm{M} \mathrm{HNO}_{3}$ at $1 \mathrm{BV} / \mathrm{hr}$ (Runs \#6 and 14), or

- staccato flow with $0.5 \mathrm{M} \mathrm{HNO}_{3}(1 \mathrm{BV} / \mathrm{hr}$ for $1 \mathrm{hr}$ then off for $3 \mathrm{hr}$ ) (Run \#4)

$0.5 \mathrm{M} \mathrm{HCOOH}$ (formic acid) at $1 \mathrm{BV} / \mathrm{hr}$ (Runs \#7 and 17)

$0.8 \mathrm{M} \mathrm{H}_{3} \mathrm{BO}_{3}$ (boric acid) at $1 \mathrm{BV} / \mathrm{hr}$ (Run 8)

$0.2 \mathrm{M} \mathrm{HNO}_{3}$ at $1 \mathrm{BV} / \mathrm{hr}($ Run \#9)

$0.1 M \mathrm{HNO}_{3}$ at $1 \mathrm{BV} / \mathrm{hr}$ (Run \#10)

$0.5 \mathrm{M} \mathrm{HNO}_{3} 11 \mathrm{BV}$ at $0.7 \mathrm{BV} / \mathrm{hr}$ (Run \#11)

$0.5 \mathrm{MHNO}_{3}$ at $2 \mathrm{BV} / \mathrm{hr}(\mathrm{Run} \# 1)$

The elution effluent for all of the continuous-flow elution runs was collected in $\sim 30$-mL portions (1.5-hr intervals) using the fraction collector. For the staccato flow and recirculating flow runs, analytical samples were collected manually. All of the loading and elution tests were performed at room temperature, which ranged from $19^{\circ} \mathrm{C}$ to $22^{\circ} \mathrm{C}$. After elution, the acid remaining in the column was displaced with deionized water (3 BV at $1 \mathrm{BV} / \mathrm{hr}$ ). For the first 14 runs, the resin was sluiced from the column at this point, and a sample of the resin was collected, air dried overnight, and submitted to RMAL for cesium and potassium analysis. For the last three runs, the resin was left in the column, regenerated using $6 \mathrm{BV}$ of $0.25 \mathrm{M} \mathrm{NaOH}$ pumped up through the resin at $2 \mathrm{BV} / \mathrm{hr}$, and then the second cesium-loading cycle was started. 


\subsection{Organic Leaching from Resin}

Samples of the various solutions that could be in contact with the resin during treatment of SRS waste were analyzed for formaldehyde (EPA Method 8315A) and VOCs (EPA Method 8260B). The solutions sampled included the water that the resin had been stored in since being manufactured, the surrogate dissolved salt solution, $0.5 M \mathrm{HNO}_{3}, 0.25 \mathrm{MNaOH}$, and $0.5 M$ formic acid. The water that had been in contact with the resin was sampled directly from the original bottle. All of the other solutions were gently mixed with the resin $(200-\mathrm{mL}$ solution to $20-\mathrm{mL}$ resin) at room temperature for $5 \mathrm{hr}$, and then samples were collected. The samples were analyzed at TestAmerica Laboratories, Inc. in Nashville, Tennessee.

\section{RESULTS AND DISCUSSION}

\subsection{Cesium Loading}

For the first two runs, multiple samples of the surrogate effluent were analyzed for cesium and potassium. The results for Run \#1 are shown in Fig. 4, and the results for Run \#2 were similar. The cesium was almost completely removed by the resin, with no sign of breakthrough, just a low leakage of cesium. Modeling by F. G. Smith of SRNL predicted a sharp breakthrough starting at $60 \mathrm{BV}$ for the conditions used in these tests, which is consistent with the experimental results since only $36 \mathrm{BV}$ were used to load the resin. The potassium showed almost complete breakthrough after only $7 \mathrm{BV}$ of surrogate, and the effluent concentration was slightly higher than the starting surrogate for samples at 10 and $13 \mathrm{BV}$, suggesting that incoming cesium displaced part of the previously loaded potassium. The initial concentrations of cesium and potassium in the surrogate were almost the same $(239 \mathrm{mg} / \mathrm{L} \mathrm{Cs}$ and $240 \mathrm{mg} / \mathrm{L} \mathrm{K})$.

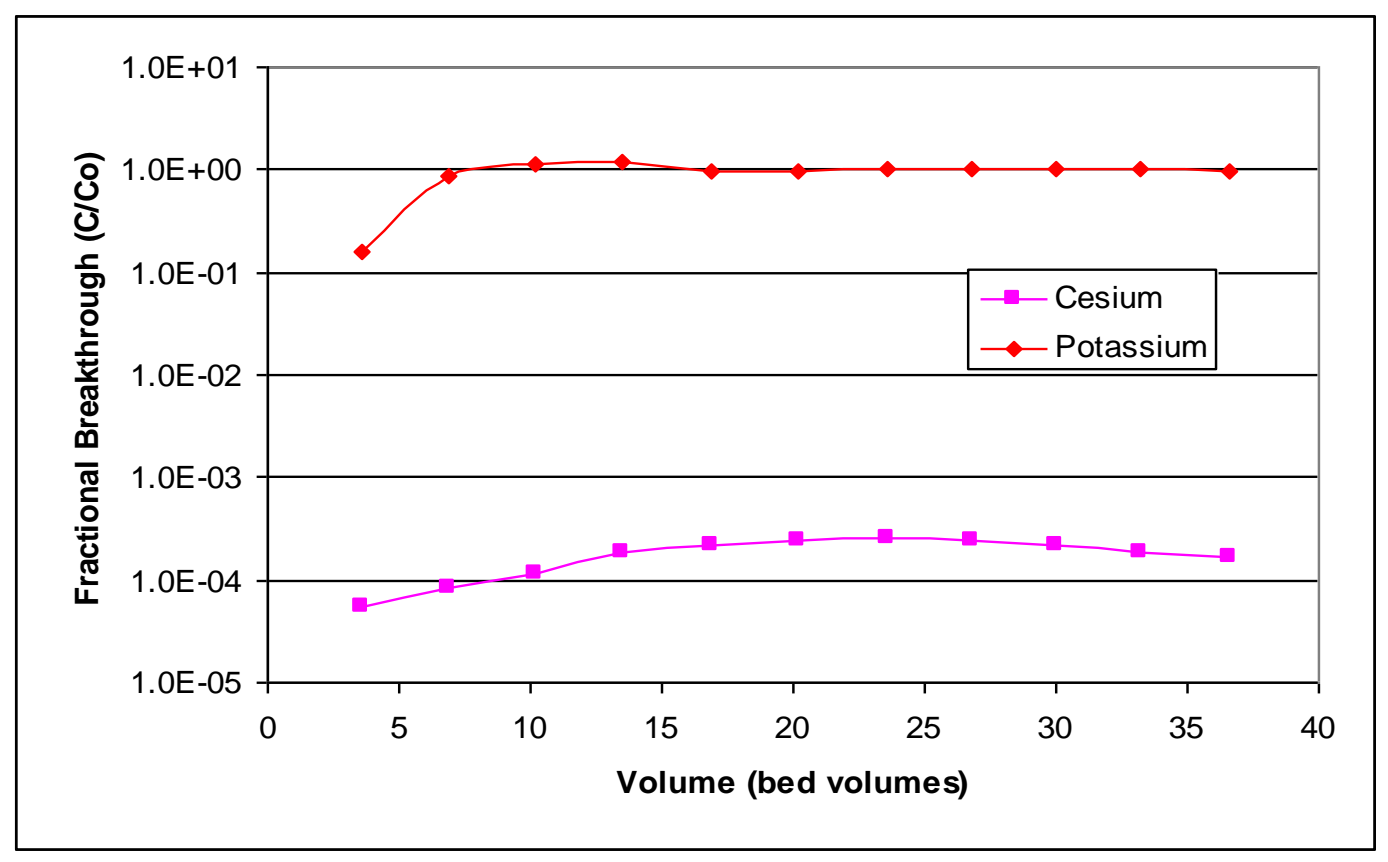

Fig. 4. Cesium and potassium loading curves for Run \#1. 
For Run \#5, which used the lower-cesium-concentration surrogate, $9075 \mathrm{~mL}$ (454 BV) of surrogate was pumped through the resin. A 3-L batch of surrogate was prepared for this run, with an initial cesium concentration of $26 \mathrm{mg} / \mathrm{L}$. Each batch of effluent was sampled for analysis of the cesium and potassium concentration, and then $26 \mathrm{mg} / \mathrm{L}$ of cesium was added to the remaining effluent, and it was returned to the feed bottle. The results for all of these samples were not received until after the run was complete. After $200 \mathrm{BV}$ of surrogate had been pumped through the column, the cesium concentration in the effluent started to increase significantly. The cesium concentration of each batch of feed solution was calculated from the measured cesium concentration in the effluent plus the $26 \mathrm{mg} / \mathrm{L}$ cesium added and the volume ratio of the effluent and remaining feed that were mixed together. The calculated cesium concentration in the feed solution also started increasing, since a constant amount of cesium was added back to each batch of effluent. Figure 5 shows a plot of the measured effluent cesium concentrations, the calculated feed concentrations, and the calculated fractional breakthrough $(\mathrm{C} / \mathrm{Co})$. The run achieved $80 \%$ breakthrough of the cesium, although the breakthrough curve was erratic for the later part of the test, probably due to the changing cesium concentration in the feed solution.

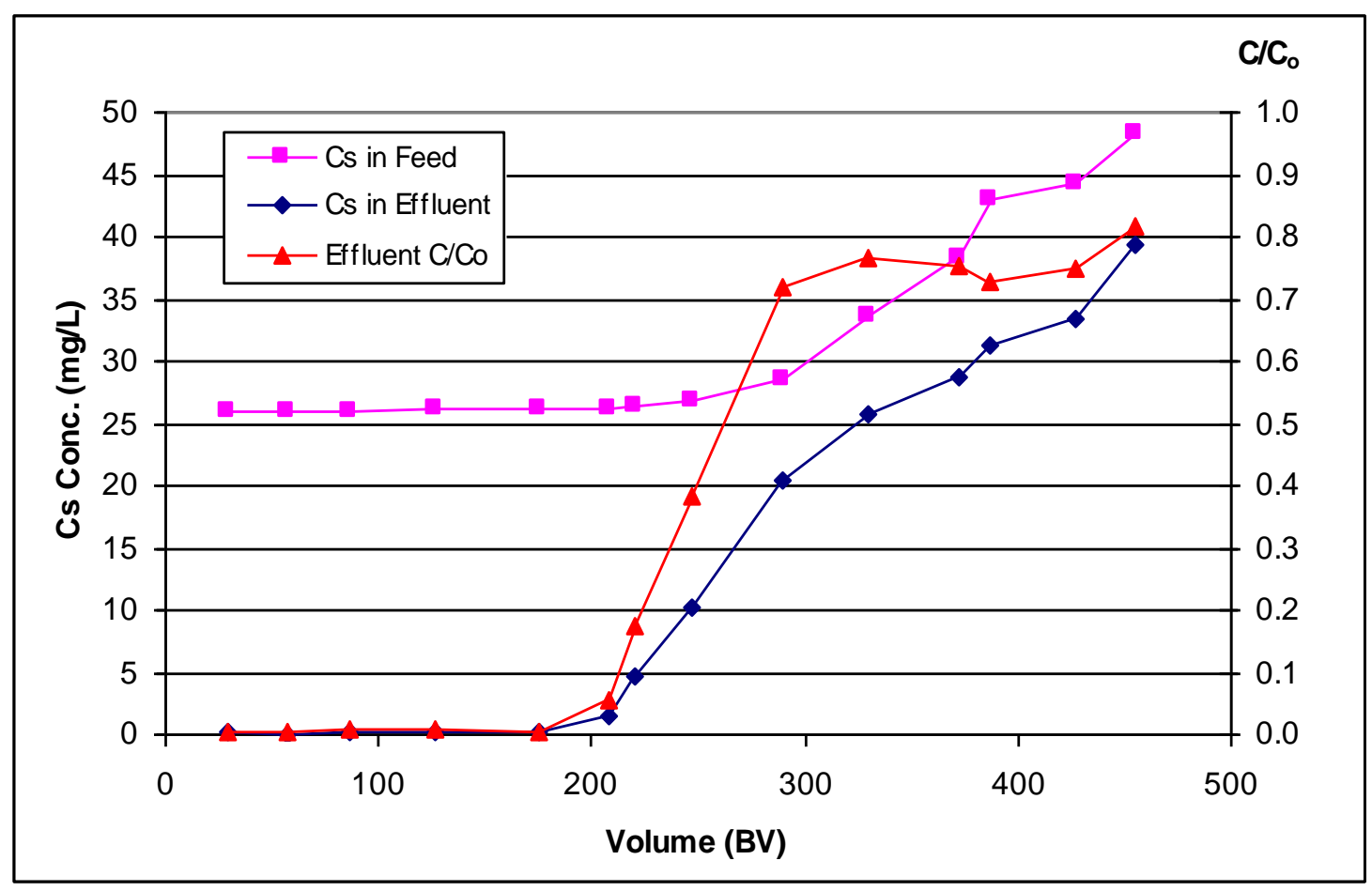

Fig. 5. Cesium breakthrough data for Run \#5.

The cesium loading for Run \#5 was lower than for the other runs (158 mg Cs or $7.95 \mathrm{~g} \mathrm{Cs} / \mathrm{L}$ resin), since only a portion of the cesium in the feed solution was retained on the resin. The resin slowly expanded during the extended contact with the surrogate solution. At the beginning of the surrogate treatment, just after converting the resin to the sodium form, the resin volume was $19.9 \mathrm{~mL}$, and at the end of the loading cycle, the volume was $25.5 \mathrm{~mL}$, a $28 \%$ increase. For the other runs, where the resin was in contact with the surrogate for only $20 \mathrm{hr}$, the resin volume 
after the loading phase was the same as the initial sodium-form volume. Testing at Hanford ${ }^{5}$ has shown that the RF resin will react with dissolved oxygen from the solutions in contact with the resin, and that the resin beads will swell as the oxygen uptake increases. The long contact time during the extended loading period would increase the amount of oxygen that contacted the resin, causing the resin expansion. Oxygen uptake also affects the cesium capacity of the resin; however, it is not possible to determine from this one test whether the capacity has been reduced, since cesium was still loading at the end of the test.

For all of the remaining runs, only one composite sample of the effluent was analyzed. The cesium concentration in the samples ranged from 0.04 to $0.34 \mathrm{mg} / \mathrm{L}$, with an average of $0.27 \mathrm{mg} / \mathrm{L}$, which gives an average decontamination factor (DF) of 888 from the feed concentration. The first 14 runs used resin that was loaded into the column in the hydrogen form and then regenerated to the sodium form before starting the loading cycle. The last three runs used resin that was converted to the sodium form in a batch mode, and then cycled through the hydrogen form and back to the sodium form in the column, using a procedure developed by SRS and Hanford personnel, prior to starting the loading. For the first 14 runs, the average cesium concentration in the effluent was $0.28 \mathrm{mg} / \mathrm{L}$, and for the last three runs, the cesium concentration averaged $0.23 \mathrm{mg} / \mathrm{L}$. A t-test analysis of variance shows that there is a $40 \%$ probability that this difference in cesium concentrations is caused by random variation, rather than any real difference caused by the resin pretreatment methods. For the high cesium surrogate solution used in these tests, the extensive resin preparation procedure used for testing at SRS and Hanford does not produce a statistically significant improvement in the cesium concentration of the effluent solutions. These tests do not provide any data on any potential impact of the resin pretreatment process on the amount of solution that can be treated prior to breakthrough, since all of the tests using the high cesium solution were stopped well before breakthrough would have occurred.

For a few of the runs, a portion of the resin bed floated for the first few hours after introduction of the surrogate solution (Fig. 6). It appears that until the higher density salt solution displaced the sodium hydroxide inside the resin beads, the resin beads with sodium hydroxide inside were less dense than the surrogate. It is also possible that the interior of the resin beads was not completely converted to the sodium form by the $0.25 \mathrm{M} \mathrm{NaOH}$, as postulated by Fiskum et. al., ${ }^{3}$ which could cause bubbles of carbon dioxide to form inside the resin beads from the carbonate in the surrogate solution. It is not clear what the difference was between the few times the resin floated and the other runs where it did not happen.

\subsection{Cesium Elution}

Baseline Elution. The baseline elution procedure of $15 \mathrm{BV}$ of $0.5 M \mathrm{HNO}_{3}$ at $1 \mathrm{BV} / \mathrm{hr}$, which was used in four tests (Runs \#2, 5, 12, and 15), produces a very sharp cesium spike at 3-4.5 BV, just as the $\mathrm{pH}$ of the effluent acid drops. The sodium concentration in the eluent was not measured directly, but the drop in $\mathrm{pH}$ indicates when most of the sodium on the resin has been displaced. Since the total volume of the column is almost two times the volume of the resin bed, the first $2 \mathrm{BV}$ of effluent are mostly displaced deionized water from the column, although there would be some mixing of the water and acid in the head space of the column above the resin. Figure 7 shows the $\mathrm{pH}$ and cesium and potassium concentrations of the eluent samples for the first 


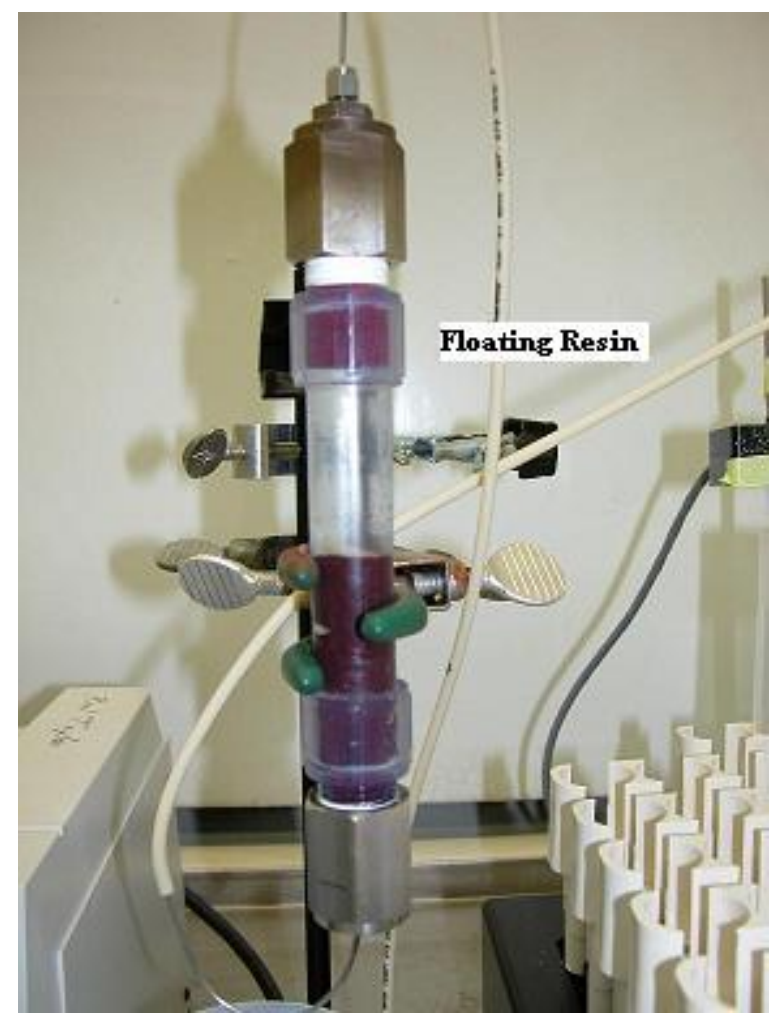

Fig. 6. Floating resin at start of loading cycle.

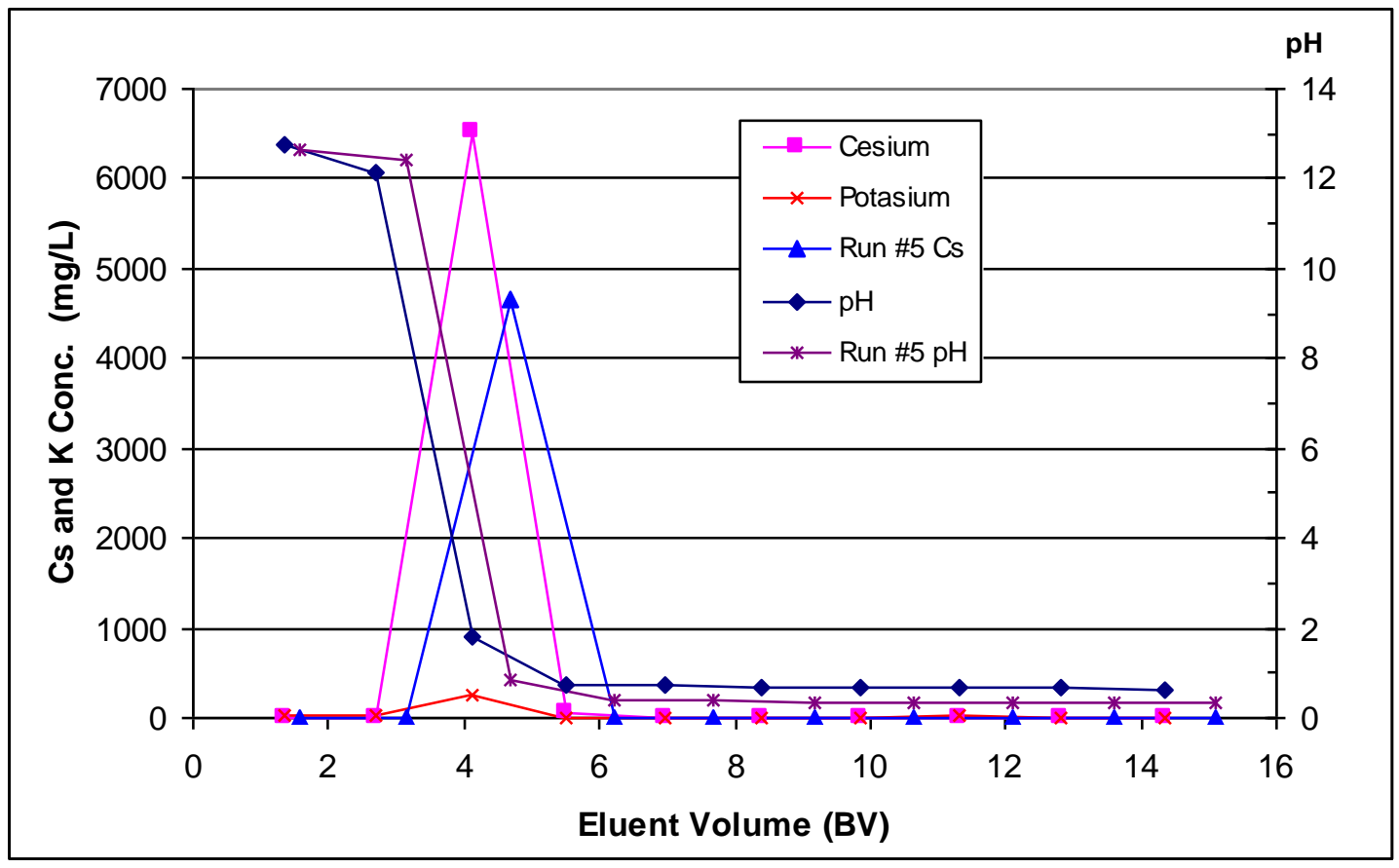

Fig. 7. Results for baseline elution procedure (Runs \#2 and 5). 
baseline run. It also shows the cesium concentration and $\mathrm{pH}$ in the eluent from Run \#5, which used the lower-cesium-concentration surrogate over an extended time period to load the resin.

Appendix A shows semi-log plots of all of the elution graphs, which emphasize the small differences in the cesium concentrations during the last part of the elutions. Appendix B shows tables of all of the analytical data for the loading and elution tests. For Run \#2, the eluent sample from 2.5 to $3.8 \mathrm{BV}$ contained $98 \%$ of all of the cesium eluted and $81 \%$ of the potassium eluted. The Run \#5 eluent samples contained lower concentrations of cesium, since the amount of cesium loaded on the resin was lower (see Sect. 3.1); however, the elution pattern was essentially the same, with $99 \%$ of the cesium in the sample collected from 3.2-4.7 BV. The peak cesium concentration for Run \#5 is slightly offset from the Run \#2 peak due to a slight difference in the effluent volumes when the samples were taken; however, there is no evidence that the accelerated loading procedure used for most of the runs changed the elution results. The baseline elution procedure was used for a total of four runs. Analysis of the resin after elution showed that the cesium concentration remaining on the resin was very low, $0.008-0.033 \mathrm{ppm}$ (>99.9999\% removal).

Lower Nitric Acid Concentrations. A total of three elutions (Runs \#3, 13, and 16) were performed using $0.5 \mathrm{MHNO}_{3}$ to titrate the resin and remove most of the cesium from the resin, and then switching to $0.05 \mathrm{MHNO}_{3}$ to complete the elution. The cesium elution pattern is very similar to that of the baseline procedure; however, it would produce about $66 \%$ less nitrate in the eluent solution. This appears to be one of the more promising methods for reducing the amount of nitrate that would be sent to DWPF from eluting the RF resin. The results for the first test of this procedure, along with the baseline results for comparison, are shown in Fig. 8, and the other two tests were similar. Analysis of the resin after elution showed that the cesium concentration remaining on the resin was quite low $(0.03-0.35 \mathrm{ppm})$, although slightly higher than that for the baseline elutions. The cesium concentration on the resin prior to elution is about $20,000 \mathrm{ppm}$, so $>99.998 \%$ of the cesium was removed during the elutions.

Tests were also completed using $0.2 M$ (Run \#9) and $0.1 M$ (Run \#10) $\mathrm{HNO}_{3}$ to elute the resin. With the lower concentrations of nitric acid, it takes more volume to titrate the resin and start eluting the cesium, and the cesium peak is lower and broader, as shown in Fig. 8. The amount of cesium left on the resin after elution was very low for both of these tests $(0.4$ and $0.5 \mathrm{ppm})$, which is $>99.997 \%$ removal. If the same volume of acid is used as for the baseline $0.5 M \mathrm{HNO}_{3}$, which was the case for these tests, using $0.2 \mathrm{M} \mathrm{HNO}_{3}$ would reduce the nitrate in the eluent stream by $60 \%$, and using $0.1 M \mathrm{HNO}_{3}$ would reduce the nitrate by $80 \%$. With the $0.1 M \mathrm{HNO}_{3}$, the bulk of the cesium is removed shortly before the elution is completed, so there is very little safety factor, unless a larger volume of acid is used. 


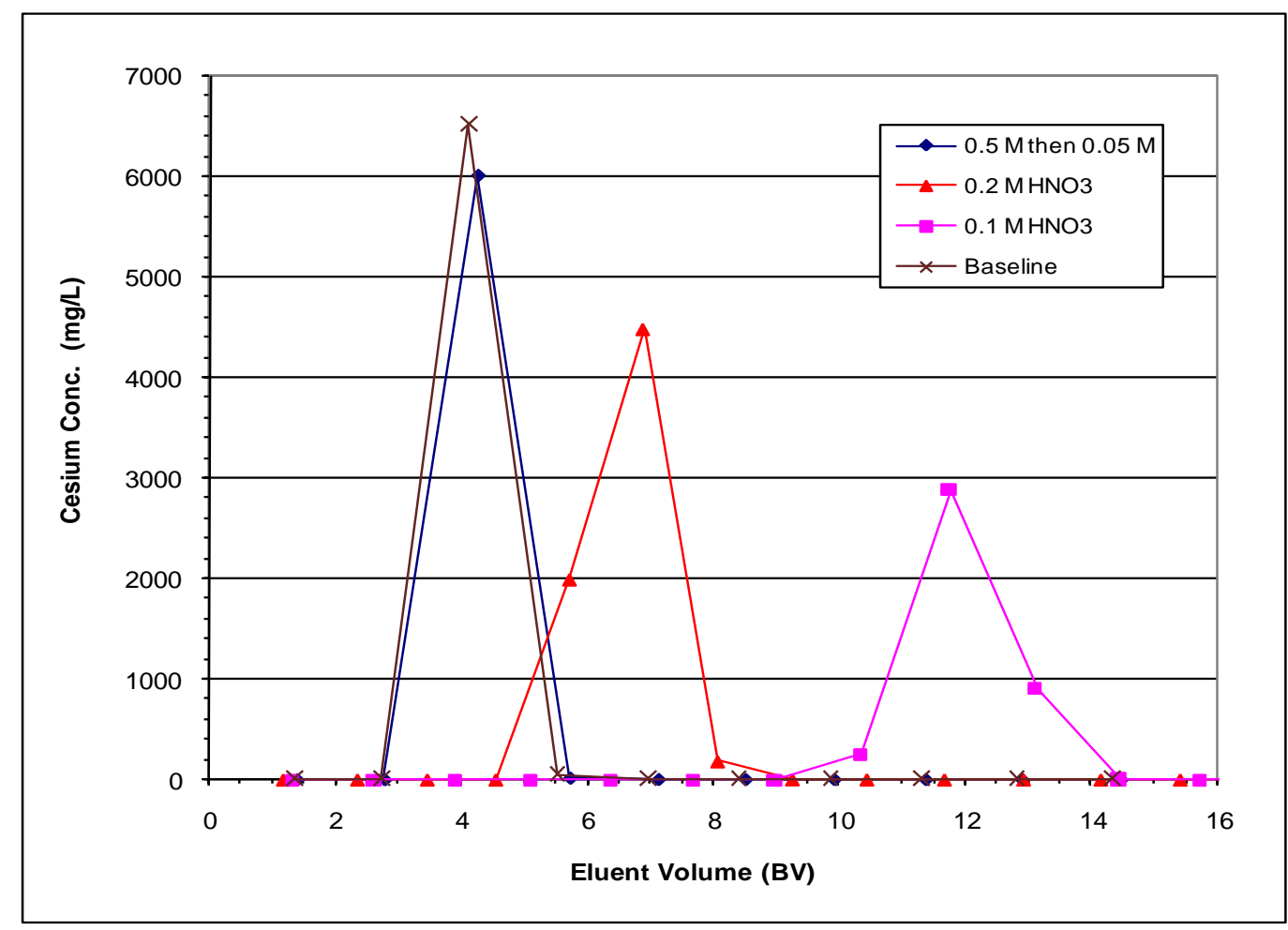

Fig. 8. Cesium results for elutions with lower concentrations of nitric acid (Runs $\# 2,3,9$, and 10).

Alternate Flow Regimes. The first test of recirculating $0.5 M \mathrm{HNO}_{3}(2.7 \mathrm{BV}$ or acid recirculating at $1 \mathrm{BV} / \mathrm{hr}$ ) following $3 \mathrm{BV}$ of once-through $0.5 \mathrm{MNO}_{3}$ (Run \#6) started the recirculation too soon, before the cesium concentration of the effluent was low, so a relatively high cesium concentration was present in the recirculating acid. For this test, a total of $5.7 \mathrm{BV}$ of acid was used, and only $95 \%$ of the cesium originally loaded on the resin was eluted. This test was repeated (Run \#14), using 4.7 BV of acid before the recirculation was started and a total of 7.0 BV of acid. The acid was recirculated through the column at $1 \mathrm{BV} / \mathrm{hr}$ for $15 \mathrm{hr}$, with small samples removed from the feed container after 1, 2, 4, 6, 9, 12, and $15 \mathrm{hr}$. The cesium concentration in the recirculating solution remained low, increasing from $0.6 \mathrm{mg} / \mathrm{L}$ to $1.2 \mathrm{mg} / \mathrm{L}$, as a small amount of cesium continued to be eluted from the resin. The cesium concentration left on the resin after elution was $3.98 \mathrm{ppm}(99.98 \%$ removal), which is significantly higher than that for most of the other elution methods tested but still relatively low in absolute terms.

One test (run \#1) was conducted using 0.5 $\mathrm{MHNO}_{3}$ at twice the normal flow rate $(2 \mathrm{BV} / \mathrm{hr})$. The cesium peak occurred in the sample from 3.2-4.8 BV (Fig. 9), which is later than for the baseline flow rate of $1 \mathrm{BV} / \mathrm{hr}$. Appendix A shows semi-log plots of all of the elution graphs, which emphasize the small differences in the cesium concentrations during the last part of the elutions. The amount of cesium left on the resin after elution was $0.275 \mathrm{ppm}$ (99.999\% removal). This elution method would require less time to complete the elution but uses the nitric acid less efficiently. 
One test (Run \#11) was conducted using $0.5 \mathrm{MHNO}_{3}$ at a lower flow rate, which averaged $0.56 \mathrm{BV} / \mathrm{hr}$, with a range of 0.47 to $0.64 \mathrm{BV} / \mathrm{hr}(0.16-0.22 \mathrm{~mL} / \mathrm{min})$. The pump speed for this test was at the lower range of the pump's ability to control, so there was more variation than for the other tests. The cesium elution peak was sharper than that for the higher flow rate, but it was similar to the baseline flow rate of $1 \mathrm{BV} / \mathrm{hr}$. The cesium peak was split between two samples, so the maximum cesium concentration was a little lower than for the baseline elution, which is shown for comparison. The amount of cesium left on the resin after elution was $0.076 \mathrm{ppm}$ (99.9997\% removal). A total of $224 \mathrm{~mL}(11 \mathrm{BV})$ of acid was used in the elution, which is $27 \%$ less than for the baseline elution method.

One test (Run \#4) used $0.5 \mathrm{MHNO}_{3}$ in a staccato flow mode (1 hr on at $1 \mathrm{BV} / \mathrm{hr}$, followed by $3 \mathrm{hr}$ off) after the resin had been titrated using a continuous flow of $5.7 \mathrm{BV}$ of acid at $1 \mathrm{BV} / \mathrm{hr}$. This procedure displaces the acid that is in contact with the resin and then lets the new acid soak for $3 \mathrm{hr}$ before displacing that acid with fresh acid. The elution curve is shown in Fig. 9. The high cesium peak was split between two samples, collected during the continuous-flow part of the run, so the peak is lower and broader. The amount of cesium left on the resin after elution was $0.044 \mathrm{ppm}$ (99.9998\% removal). A total of $240 \mathrm{~mL}$ (12 BV) of acid was used in the elution, which is $20 \%$ less than for the baseline elution method. We did not try a test using $240 \mathrm{~mL}$ of $0.5 \mathrm{M} \mathrm{HNO}_{3}$ at $1 \mathrm{BV} / \mathrm{hr}$ (baseline elution procedure with a lower volume of acid); however, analytical results are available for the concentration of cesium in the elution samples from $12 \mathrm{BV}$ through $15 \mathrm{BV}$. The average cesium concentration was $0.07 \mathrm{mg} / \mathrm{L}$, which would represent a concentration of $0.56 \mathrm{ppm}$ Cs on the resin that was removed by the last three bed volumes of acid. Since this concentration is significantly higher than the cesium concentration left on the resin by the staccato flow procedure using $12 \mathrm{BV}$ of acid, the staccato flow method uses the acid more efficiently. 


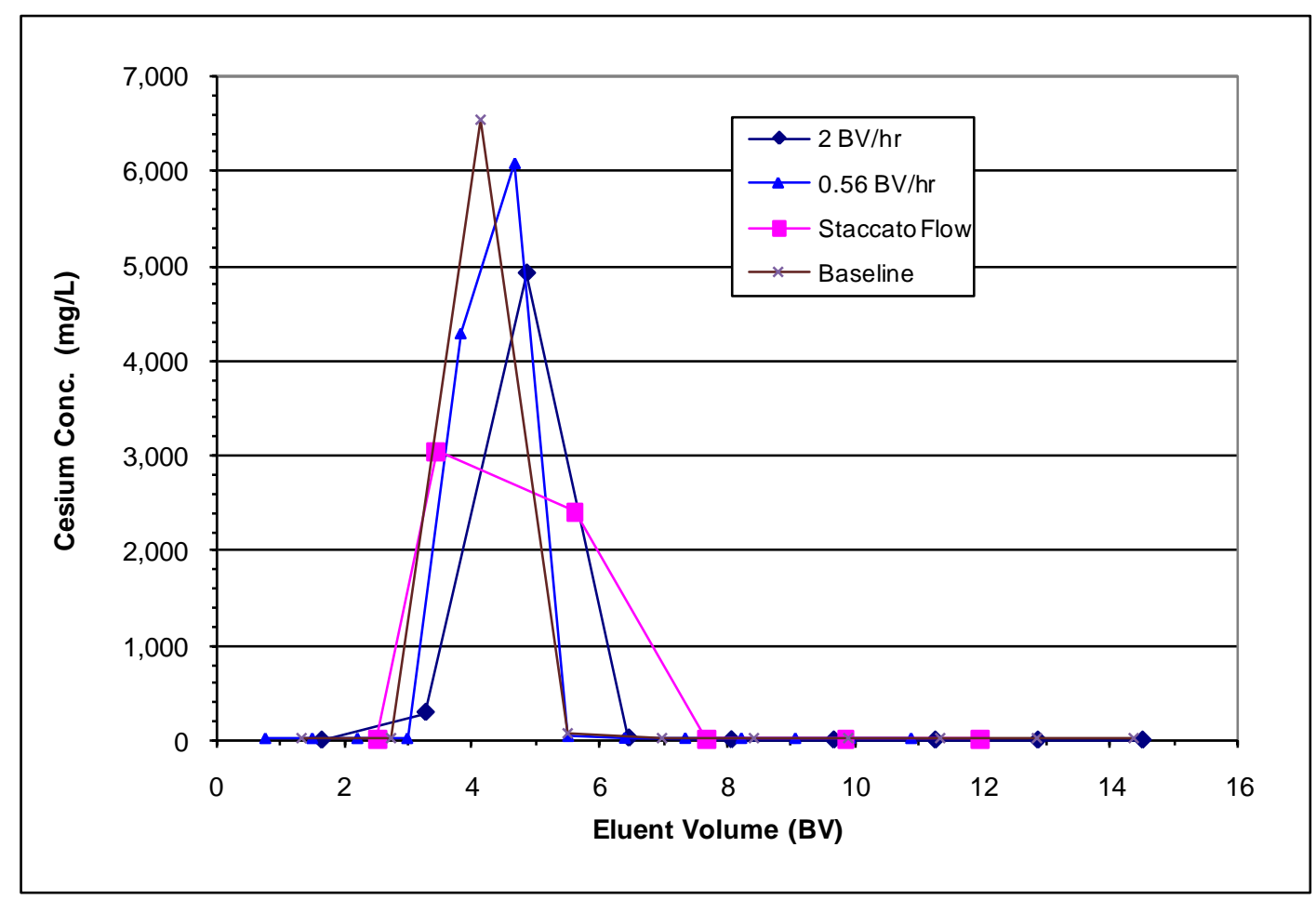

Fig. 9. Results for elution with $0.5 \mathrm{MHNO}_{3}$, using alternate flow regimes (Runs \#1, 2, 4, and 11).

Alternate Acids. Two potential alternative acids (formic acid and boric acid) were identified based on their likely compatibility with DWPF and the SRS tank farm.

Formic acid $(\mathrm{HCOOH})$ is currently used at DWPF to control the redox potential of the feed stream to the glass melter. Formic acid is the simplest and most acidic $(\mathrm{pKa}=3.74)$ of the carboxylic acids and is completely miscible with water. ${ }^{6}$ Formic acid $(0.5 \mathrm{M})$ solution was pumped through the column at $1 \mathrm{BV} / \mathrm{hr}$ to elute the $\mathrm{RF}$ resin. This solution would have a free hydrogen ion concentration of $0.0095 \mathrm{M}$; however, when in contact with the high $\mathrm{pH}$ resin, the formic acid would supply a higher amount of hydrogen ions, as the resin exchanges the hydrogen ions from the solution for sodium ions initially on the resin. After the resin is converted to mostly the hydrogen form (titrated), the amount of hydrogen ions supplied by the formic acid solution would drop to about $0.0095 \mathrm{M}$. Figure 10 shows the cesium and potassium concentrations and $\mathrm{pH}$ of the formic acid eluent solutions. The amount of solution required to titrate the resin and elute most of the cesium is only slightly higher than for the baseline $(0.5 \mathrm{M}$ $\mathrm{HNO}_{3}$ ) solution. For unknown reasons, the cesium peak for Run \#7 was slower than for Run \#17 and was split between two samples. The amount of cesium remaining on the resin $(5.7 \mathrm{ppm}$, 99.98\% removal for Run \#7) was significantly higher than that for the baseline elution method, although it was still relatively low. SRS personnel have not determined the maximum amount of formic acid that could be accommodated at DWPF. A higher concentration of formic acid could potentially be used, which should improve the elution results. 


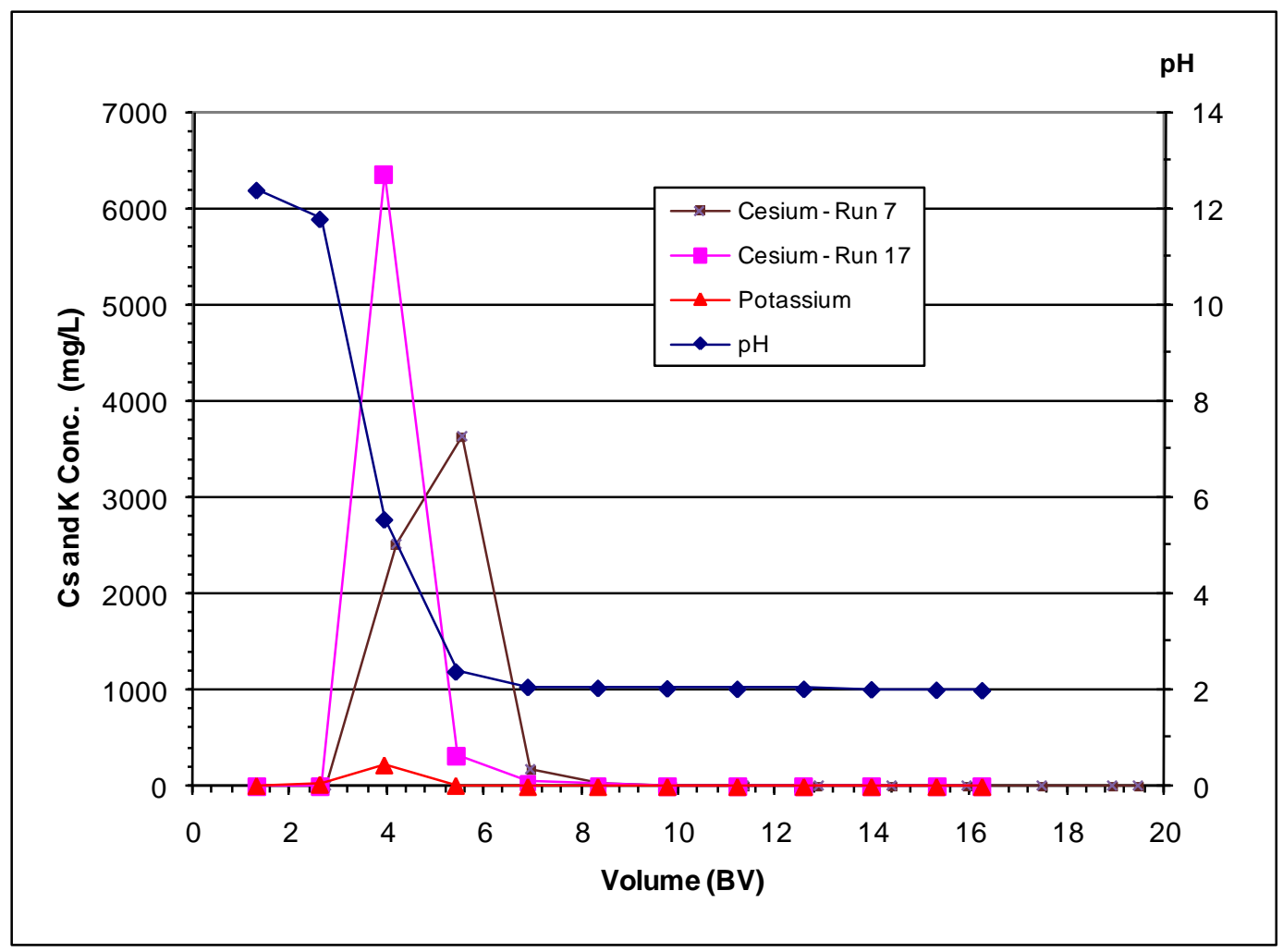

Fig. 10. Results for elution with $0.5 M$ formic acid solution (Runs \#7 and 17).

Boric acid does not dissociate in aqueous solution, but it is slightly acidic (pKa of 9.24) due to its interaction with water molecules: $\mathrm{B}(\mathrm{OH})_{3}+\mathrm{H}_{2} \mathrm{O} \rightarrow \mathrm{B}(\mathrm{OH})_{4}^{-}+\mathrm{H}^{+}$. Boric acid has a maximum solubility in water of $0.9 \mathrm{M}^{7}$ Since the cesium-loaded RF resin has a very high $\mathrm{pH}$, contact between a boric acid solution and the resin would increase the amount of hydrogen ions supplied by the solution. A solution of $0.8 \mathrm{M}$ boric acid, which has a free hydrogen ion concentration of 2.2E-5 M, was tested for eluting the resin. About $8 \mathrm{BV}$, pumped through the column at $1 \mathrm{BV} / \mathrm{hr}$, of boric acid solution was required to titrate the resin and start eluting the cesium (Fig. 11). The cesium concentration in the eluate samples was much lower than that for the other elution methods, and the elution was not complete after $18 \mathrm{BV}$. The concentration of cesium left on the resin was $9450 \mathrm{ppm}$ (73\% removal). Boric acid is not recommended for eluting cesium from the RF resin. 


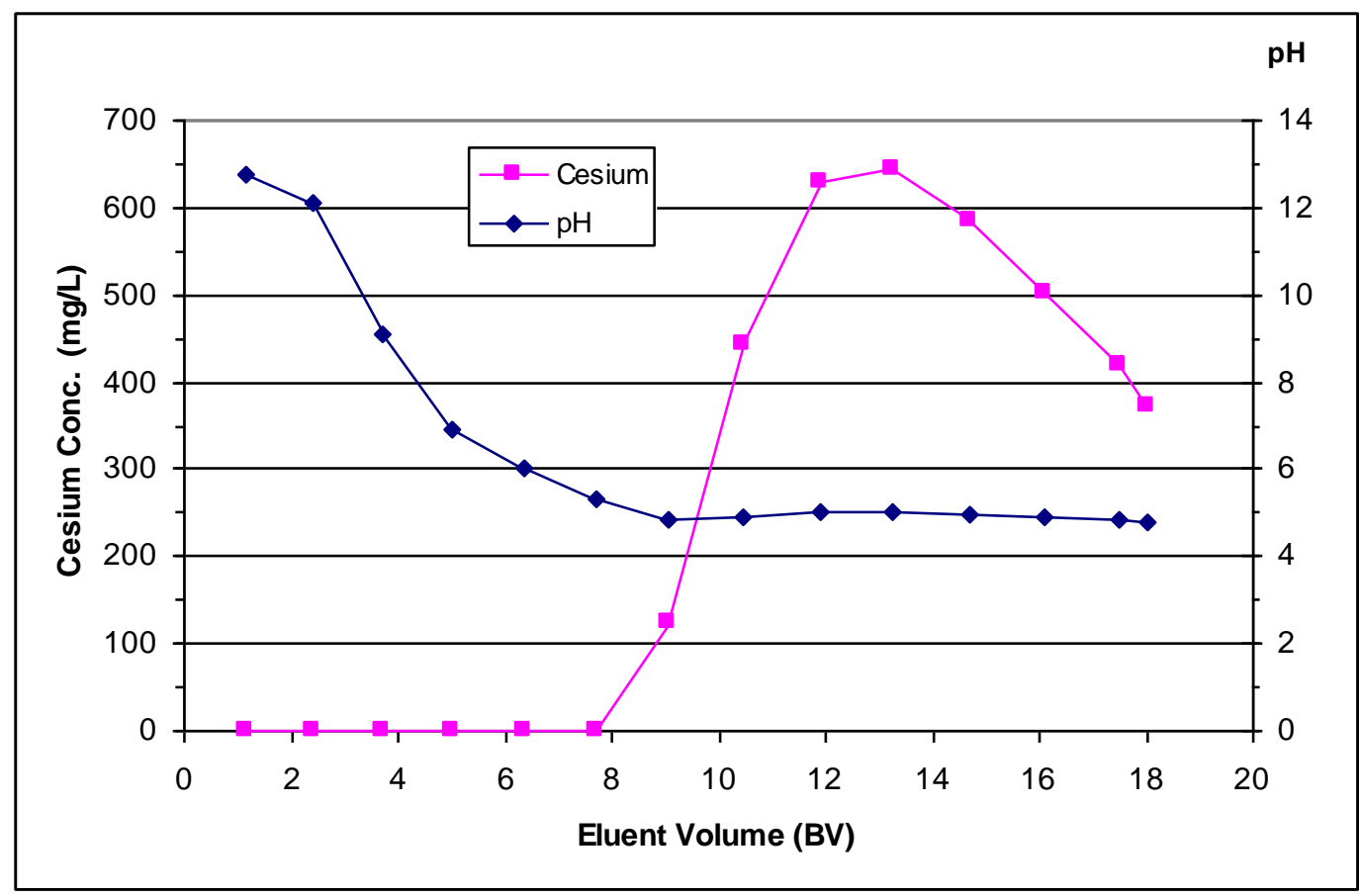

Fig. 11. Results for elution with $0.8 M$ boric acid solution (Run \#8).

Figure 12 shows the elution results for the baseline, staccato flow, $0.5 M \mathrm{HNO}_{3}$ followed by $0.05 \mathrm{MHNO}_{3}$, and $0.5 \mathrm{M}$ formic acid elution methods on a semi-log scale, which emphasizes the small differences in the cesium concentration at the end of the elution cycles. The cesium concentrations in the solutions at the end of the elution cycles correlate well with the amount of cesium left on the resin after the elution (Table 4 and Fig. 12).

Table 4. Cesium concentrations left on resin after elutions

\begin{tabular}{lc}
\hline \multicolumn{1}{c}{ Elution method } & $\begin{array}{c}\text { Cesium concentration on resin } \\
(\mathbf{p p m})\end{array}$ \\
\hline $0.5 \mathrm{MHNO}_{3}-$ Baseline (Run \#15) & 0.013 \\
$0.5 \mathrm{MHO}_{3}-$ staccato flow (Run \#4) & 0.044 \\
$0.5 \mathrm{MNO}_{3}$ then $0.05 \mathrm{MNO}_{3}$ (Run \#3) & 0.348 \\
$0.5 \mathrm{M}$ formic acid (Run \#17) & 5.70 \\
\hline
\end{tabular}




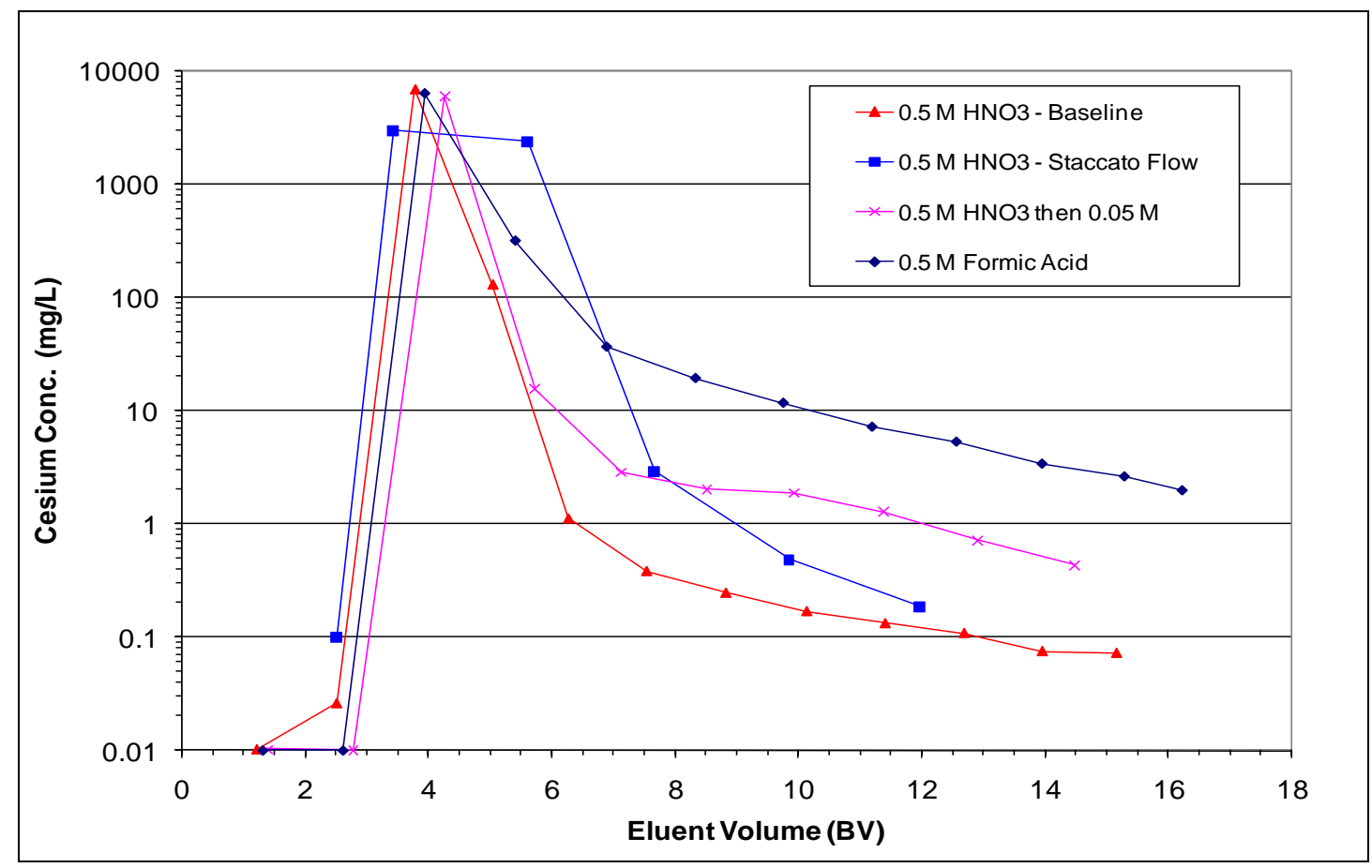

Fig. 12. Results for various elution methods (Runs \#3, 14, 15, and 17).

\subsection{Second Cesium Loading Cycle}

The last three tests used (1) the baseline procedure (Run \#15), (2) $0.05 M \mathrm{HNO}_{3}$ following the initial titration by $0.5 \mathrm{MHNO}_{3}$ (Run \#16), and (3) $0.5 \mathrm{M}$ formic acid (Run \#17) for eluting the cesium from the resin. For each of these tests, a second loading cycle, using a lower-cesiumconcentration surrogate, was performed to measure any impact of the first elution on the initial phase of the next loading cycle. After the elution step, the acid was displaced by deionized water, $3 \mathrm{BV}$ downflow at $1 \mathrm{BV} / \mathrm{hr}$, and then the resin was converted to the sodium form (regenerated) by $6 \mathrm{BV}$ of $0.25 \mathrm{M} \mathrm{NaOH}$ pumped upflow at $2 \mathrm{BV} / \mathrm{hr}$. The second loading cycle used a surrogate salt solution with $55 \mathrm{mg} / \mathrm{L} \mathrm{Cs}$, which was pumped down through the column at $2 \mathrm{BV} / \mathrm{hr}$. The fraction collector was used to collect composite samples of the effluent surrogate every hour.

Direct measurement of the surrogate effluent samples using the most sensitive method available gave non-detects $(<5 \mu \mathrm{g} / \mathrm{L})$ for the cesium concentration in all of the samples from Runs \#15 and 16. The detection limit for these samples is mostly driven by the high sodium concentration $(\sim 6 M)$ in the surrogate solution. In order to improve the detection limit for cesium, the effluent samples were composited into early (0-7 BV), middle (7-18 BV), and late (18-28 BV) samples. Each of the composite samples $(\sim 55 \mathrm{~mL})$ was batch-contacted for $24 \mathrm{hr}$ with about $0.3 \mathrm{~g}$ of RF resin. Each resin sample was rinsed with $1 \mathrm{M} \mathrm{NaOH}$, and then with deionized water, and the resin was then eluted with $25 \mathrm{~mL}$ of $1 M \mathrm{HNO}_{3}$ (24-hr batch contact). This treatment approximately doubled the cesium concentration from the surrogate effluent samples and greatly reduced the sodium concentration. The cesium concentrations in the eluate solutions for Runs \#15 and 16 ranged from 5.3-8.5 $\mu \mathrm{g} / \mathrm{L}$. After applying the concentration factor (surrogate 
volume/ acid volume) for each sample, the cesium concentrations in the surrogate effluent composites were calculated to range from 3.3-5.0 $\mu \mathrm{g} / \mathrm{L}$ with no systematic trend for the early, middle, and late samples from either run. For the Run \#17 samples, the calculated cesium concentration in the original surrogate effluent samples ranged from 15.1-24.0 $\mu \mathrm{g} / \mathrm{L}$ with no systematic trend for the early, middle, and late samples. The average cesium concentration for the Run \#15 samples was $4.2 \mu \mathrm{g} / \mathrm{L}$, and the average for the Run \#16 samples was $4.1 \mu \mathrm{g} / \mathrm{L}$. A $\mathrm{t}$-test analysis of variance shows that there is a $46 \%$ probability that this difference in cesium concentrations is caused by random variation, rather than any real difference caused by the elution methods. Therefore, the baseline elution procedure and the procedure using $0.05 \mathrm{M}$ $\mathrm{HNO}_{3}$ following the initial titration by $0.5 M \mathrm{HNO}_{3}$ show the same performance for the subsequent cesium-loading cycle. The average cesium concentration for Run \#17 was $18.5 \mu \mathrm{g} / \mathrm{L}$, which is significantly higher than the Runs \#15 and 16 results. The average cesium DF for Runs \#15 and 16 (up through 28 BV of surrogate treated) was 13,200, and the DF for Run \#17 was 3000 . The average DF for the first loading cycle, using $36 \mathrm{BV}$ of surrogate containing $239 \mathrm{mg} / \mathrm{L}$ of cesium, was 1030. It is not known why the second loading cycle showed a much higher DF than the first loading cycle for these tests. The cesium concentration in the feed solution was different for the first and second loading cycles; however, the DF for the first $60 \mathrm{BV}$ of Run \#5, which used a cesium feed concentration $(26 \mathrm{mg} / \mathrm{L})$ even lower than for the second loading cycle in these tests, showed a DF of only 248. The resin used in these tests had been cycled twice through the hydrogen and sodium forms prior to starting the first cesium loading, so it does not seem likely that one more cycle during the elution and regeneration steps would cause a large improvement in the cesium sorption.

\subsection{Organic Leaching from Resin}

The results for the formaldehyde analyses of the solutions that were in contact with the RF resin are shown in Table 5. The water that the resin had been stored in since 2005 contained the highest concentration of formaldehyde. This water would be separated from the resin during the resin preparation procedure, which would occur away from the tank farm. The other solutions, which could be discharged into the tanks or to DWPF, contained fairly low concentrations. No other VOCs were detected in any of the samples. The detection limits for the 64 compounds listed on the VOC report, which range from 0.001 to $0.05 \mathrm{mg} / \mathrm{L}$, are listed in Appendix C.

Table 5. Formaldehyde concentrations in solutions that were in contact with the $R F$ resin

\begin{tabular}{lc}
\hline \multicolumn{1}{c}{ Solution } & Formaldehyde $(\mathbf{m g} / \mathbf{L})$ \\
\hline Salt surrogate & $<0.05$ \\
$0.5 \mathrm{M} \mathrm{NaOH}$ & 4.67 \\
$0.5 \mathrm{M} \mathrm{HNO}$ & 1.33 \\
$0.5 \mathrm{M}$ formic acid & 1.80 \\
Water from resin storage bottle & 13.6 \\
\hline
\end{tabular}

Previous work at the Hanford site ${ }^{3}$ with resin produced by SINTEF (Trondheim, Norway) in 2004 showed much higher formaldehyde concentrations $(1100-3000 \mathrm{mg} / \mathrm{L})$ in the water storage solution. 


\section{REFERENCES}

1. Fiskum, S. K., M. J. Steele, and D. L. Blanchard, Jr., Small Column Ion Exchange Testing of Spherical Resorcinol-Formaldehyde Resin for ${ }^{137}$ Cs Removal from Pre-Treated Hanford Tank 241-AN-102 Waste (Envelope C), WT-RPT-135, Rev. 1, Battelle-Pacific Northwest Division, Richland, WA, April 2006.

2. Duigan, M. R., Small Column Ion Exchange Hydraulic Test, WSRC-STI-2007-00325, Washington Savannah River Site, Aiken, SC, August 28, 2007.

3. Fiskum, S. K., et al., Comparison Testing of Multiple Spherical Resorcinol-Formaldehyde Resins for the River Protection Project-Waste Treatment Plant, WTP-RPT-143, Rev. 1, Battelle_-Pacific Northwest Division, Richland, WA, November 2006.

4. Smith, F. G., Modeling of Ion-Exchange for Cesium Removal from Dissolved Saltcake in SRS Tanks 1-3, 37 and 41, WSRC-STI-2007-00315 Rev. 0, Washington Savannah River Site, Aiken, SC, August 2007.

5. Arm, S. T., et al., Laboratory Scale Hydraulic Testing of Spherical resorcinol Formaldehyde Ion Exchange Resin, Battelle_Pacific Northwest Division, Richland, WA, September 2006.

6. Morrison, R. T. and R. N. Boyd, Organic Chemistry, 2nd Edition, Boston, Allyn and Bacon, Inc., 1970.

7. Jolly, W. L., Modern Inorganic Chemistry, 2nd Edition, New York, McGraw-Hill, 1991. 



\section{APPENDICES}



Appendix A

SEMI-LOG PLOTS OF ELUTION RESULTS

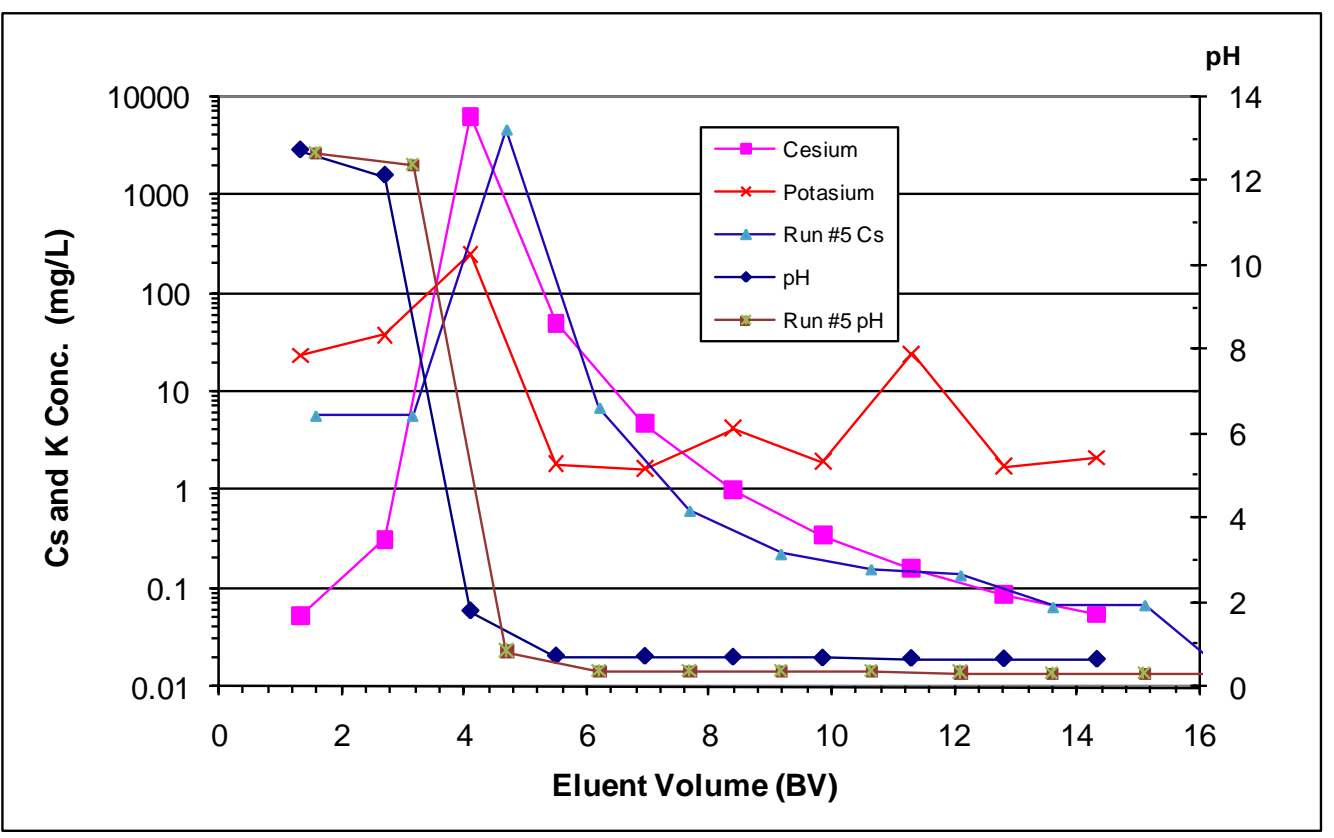

Fig. A.1. Semi-log version of Fig. 7-baseline elutions.

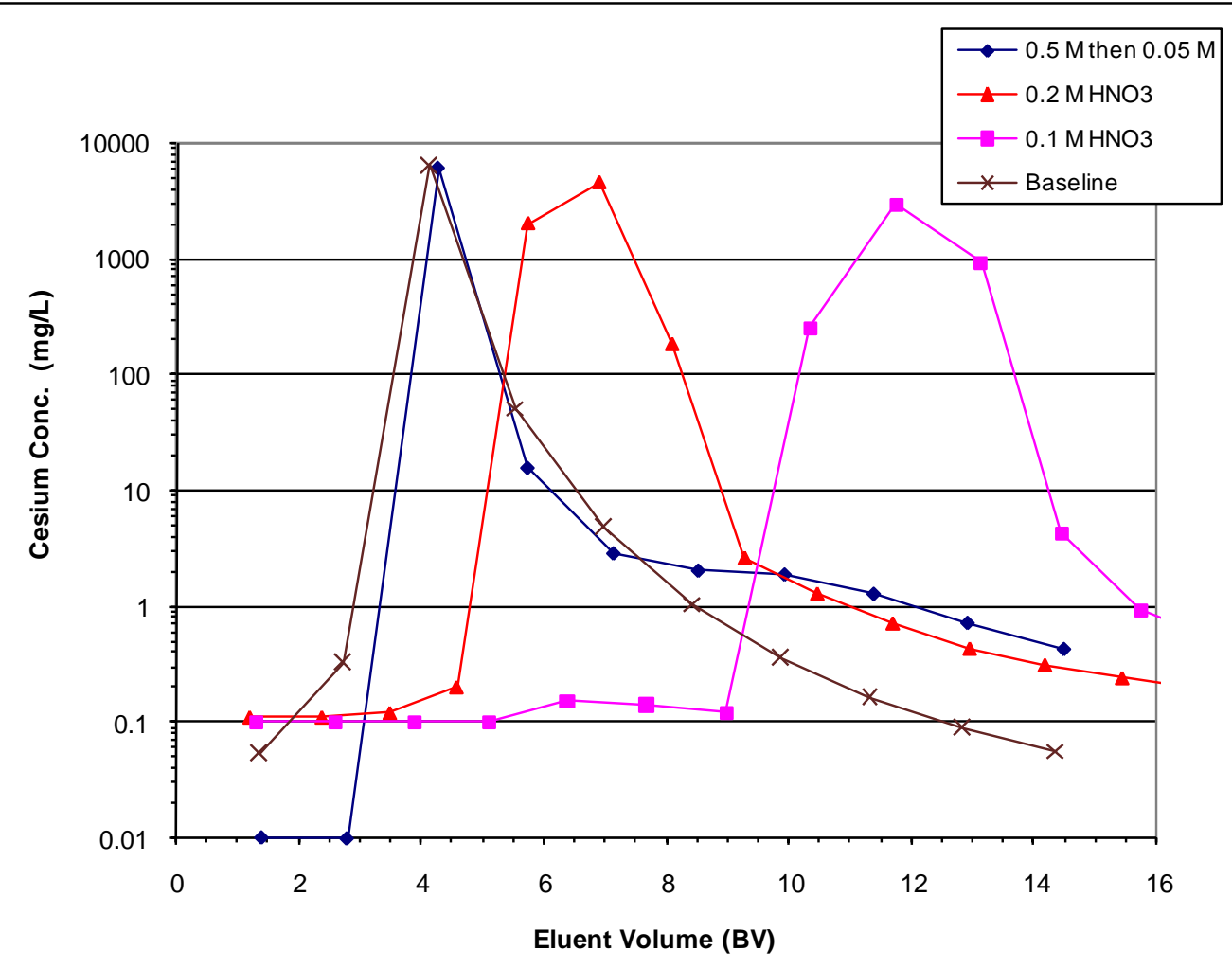

Fig. A.2. Semi-log version of Fig. 8-alternate nitric acid concentrations. 


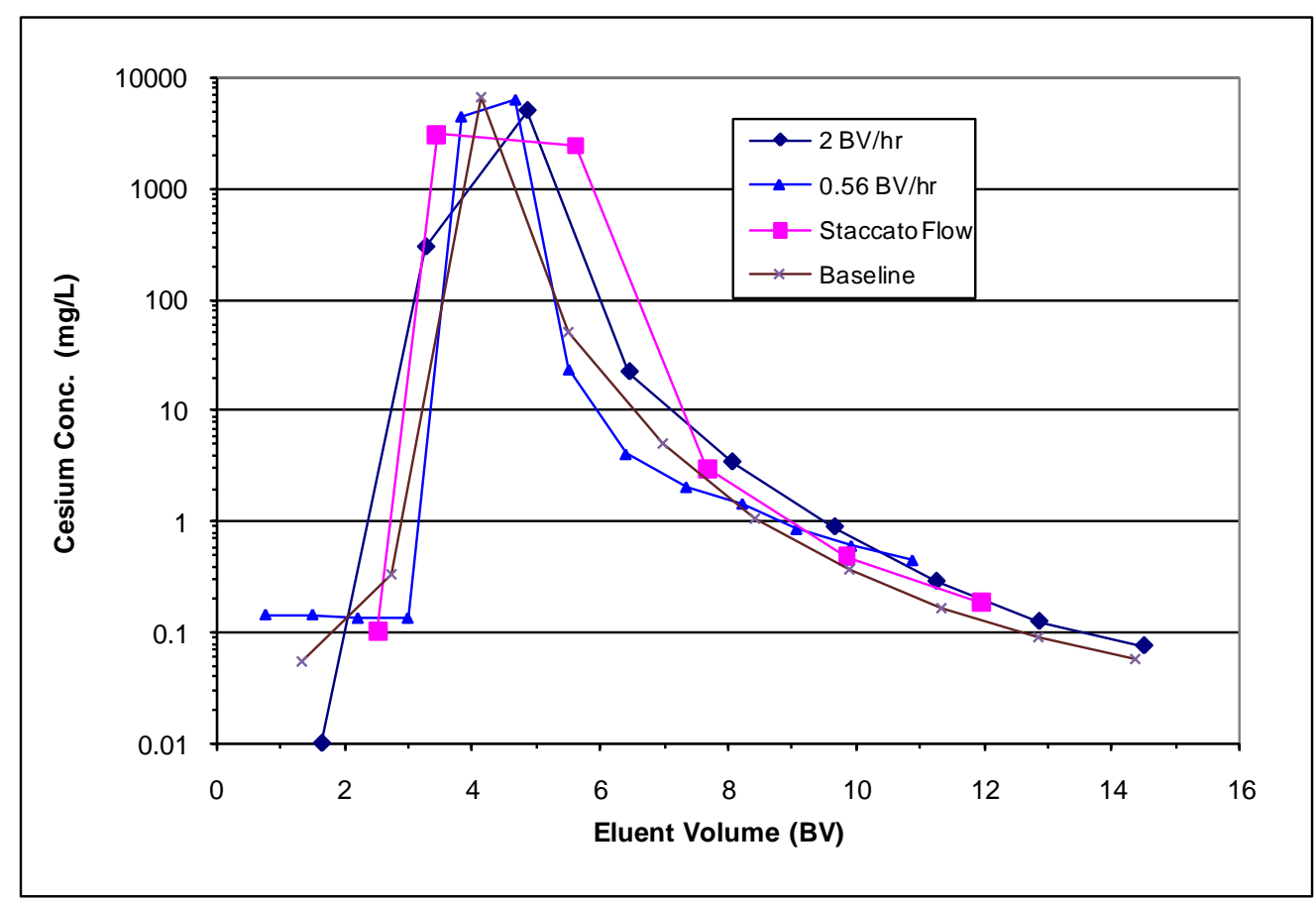

Fig. A.3. Semi-log version of Fig. 9-alternate flow regimes.

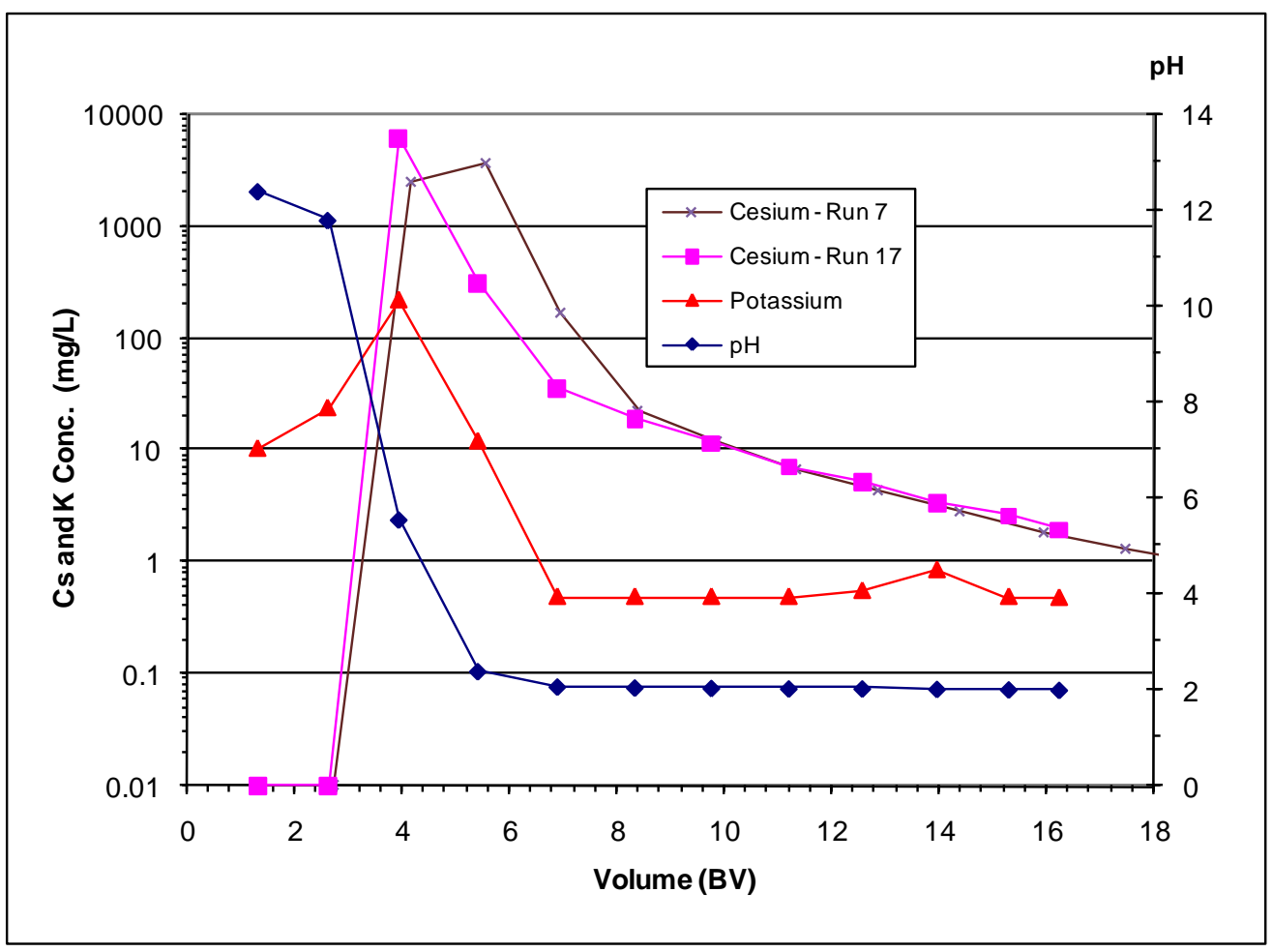

Fig. A.4. Semi-log version of Fig. 10 - formic acid elution. 
Appendix B

LISTING OF ANALYTICAL DATA FOR LOADING AND ELUTION TESTS

\begin{tabular}{|c|c|c|}
\hline \multicolumn{3}{|c|}{$\begin{array}{c}\text { Run \#1 } \\
\text { Cesium loading }\end{array}$} \\
\hline $\begin{array}{c}\text { Surrogate } \\
\text { volume } \\
(\mathrm{BV})\end{array}$ & $\begin{array}{c}{[\mathrm{Cs}]} \\
(\mathrm{mg} / \mathrm{L})\end{array}$ & $\begin{array}{c}{[\mathrm{K}]} \\
(\mathrm{mg} / \mathrm{L})\end{array}$ \\
\hline 3.55 & 0.014 & 43 \\
\hline 6.84 & 0.021 & 232 \\
\hline 10.17 & 0.028 & 301 \\
\hline 13.49 & 0.047 & 327 \\
\hline 16.86 & 0.054 & 267 \\
\hline 20.23 & 0.062 & 256 \\
\hline 23.55 & 0.064 & 269 \\
\hline 26.80 & 0.061 & 272 \\
\hline 30.03 & 0.054 & 269 \\
\hline 33.25 & 0.046 & 279 \\
\hline 36.62 & 0.041 & 265 \\
\hline
\end{tabular}

\begin{tabular}{|c|c|c|}
\hline \multicolumn{3}{|c|}{$\begin{array}{c}\text { Run \#2 } \\
\text { Cesium loading }\end{array}$} \\
\hline $\begin{array}{c}\text { Surrogate } \\
\text { volume } \\
(\mathrm{BV})\end{array}$ & $\begin{array}{c}{[\mathrm{Cs}]} \\
(\mathrm{mg} / \mathrm{L})\end{array}$ & $\begin{array}{c}{[\mathrm{K}]} \\
(\mathrm{mg} / \mathrm{L})\end{array}$ \\
\hline 2.87 & 0.430 & 21 \\
\hline 6.10 & 0.279 & 306 \\
\hline 9.35 & 0.142 & 257 \\
\hline 12.64 & 0.112 & 263 \\
\hline 15.98 & 0.190 & 264 \\
\hline 19.35 & 0.078 & 262 \\
\hline 22.78 & 0.270 & 269 \\
\hline 26.11 & 0.063 & 266 \\
\hline 29.32 & 0.059 & 266 \\
\hline 32.72 & 0.051 & 268 \\
\hline 36.44 & 0.483 & 280 \\
\hline
\end{tabular}

\begin{tabular}{|c|c|c|c|c|}
\hline \multicolumn{5}{|c|}{ Run \#1 elution } \\
\hline \multicolumn{3}{|c|}{$0.5 \mathrm{MNO}$, 2 BV/hr } \\
\hline $\begin{array}{c}\text { Eluent } \\
\text { volume } \\
(\mathrm{BV})\end{array}$ & & $\begin{array}{c}\text { [Cs] } \\
(\mathrm{mg} / \mathrm{L})\end{array}$ & & $\begin{array}{c}{[\mathrm{K}]} \\
(\mathrm{mg} / \mathrm{L})\end{array}$ \\
\hline 1.62 & $<$ & 0.01 & & 22.4 \\
\hline 3.25 & & 292 & & 49.3 \\
\hline 4.84 & & 4910 & & 180 \\
\hline 6.44 & & 22.00 & & 0.77 \\
\hline 8.04 & & 3.40 & $<$ & 0.50 \\
\hline 9.65 & & 0.89 & & 0.61 \\
\hline 11.24 & & 0.29 & $<$ & 0.50 \\
\hline 12.84 & & 0.13 & $<$ & 0.50 \\
\hline 14.48 & & 0.08 & & 0.95 \\
\hline
\end{tabular}

\begin{tabular}{|r|c|c|c|c|}
\hline \multicolumn{5}{|c|}{ Run \#2 elution } \\
\hline \multicolumn{3}{|c|}{$0.5 \mathrm{HNO}$ 3, 1 BV/hr } \\
\hline $\begin{array}{c}\text { Eluent } \\
\text { volume } \\
(\mathrm{BV})\end{array}$ & $\begin{array}{c}{[\mathrm{Cs}]} \\
(\mathrm{mg} / \mathrm{L})\end{array}$ & $\begin{array}{c}{[\mathrm{K}]} \\
(\mathrm{mg} / \mathrm{L})\end{array}$ \\
\hline 1.33 & & 0.05 & & 23.8 \\
\hline 2.71 & & 0.32 & & 38.1 \\
\hline 4.11 & & 6520 & & 255 \\
\hline 5.51 & & 50.6 & & 1.87 \\
\hline 6.96 & & 4.81 & & 1.66 \\
\hline 8.40 & & 1.02 & & 4.29 \\
\hline 9.86 & & 0.36 & & 1.97 \\
\hline 11.31 & & 0.16 & & 24.6 \\
\hline 12.82 & & 0.09 & & 1.74 \\
\hline 14.34 & & 0.05 & & 2.15 \\
\hline
\end{tabular}

B-1 


\begin{tabular}{|r|c|c|c|c|}
\hline \multicolumn{5}{|c|}{ Run \#3 } \\
\hline \multicolumn{2}{|c|}{0.5 then $0.05 \mathrm{MNO}_{3}, 1 \mathrm{BV} / \mathrm{hr}$} \\
\hline $\begin{array}{c}\text { Eluent } \\
\text { volume } \\
(\mathrm{BV})\end{array}$ & $\begin{array}{c}{[\mathrm{Cs}]} \\
(\mathrm{mg} / \mathrm{L})\end{array}$ & $\begin{array}{c}{[\mathrm{K}]} \\
(\mathrm{mg} / \mathrm{L})\end{array}$ \\
\hline 1.38 & & 0.01 & & 21.0 \\
\hline 2.77 & $<$ & 0.01 & & 39.1 \\
\hline 4.26 & & 6000 & & 260 \\
\hline 5.72 & & 15.6 & $<$ & 0.50 \\
\hline 7.12 & & 2.86 & $<$ & 0.50 \\
\hline 8.51 & & 2.03 & $<$ & 0.50 \\
\hline 9.92 & & 1.88 & $<$ & 0.50 \\
\hline 11.37 & & 1.28 & $<$ & 0.50 \\
\hline 12.90 & & 0.72 & $<$ & 0.50 \\
\hline 14.47 & & 0.43 & $<$ & 0.50 \\
\hline 16.06 & & 0.21 & $<$ & 0.50 \\
\hline
\end{tabular}

\begin{tabular}{|r|c|c|c|c|}
\hline \multicolumn{5}{|c|}{ Run \#5 } \\
\multicolumn{2}{|c|}{ Extended run, baseline elution } \\
\hline $\begin{array}{c}\text { Eluent } \\
\text { volume } \\
(\mathrm{BV})\end{array}$ & $\begin{array}{c}{[\mathrm{Cs}]} \\
(\mathrm{mg} / \mathrm{L})\end{array}$ & $\begin{array}{c} \\
{[\mathrm{K}]} \\
(\mathrm{mg} / \mathrm{L})\end{array}$ \\
\hline 1.57 & 5.73 & & 41.8 \\
\hline 3.15 & 5.72 & & 37.3 \\
\hline 4.69 & 4650 & & 93.9 \\
\hline 6.21 & 6.92 & $<$ & 0.50 \\
\hline 7.68 & & 0.62 & $<$ & 0.50 \\
\hline 9.17 & & 0.23 & & 1.10 \\
\hline 10.64 & & 0.16 & & 2.47 \\
\hline 12.10 & & 0.14 & $<$ & 0.50 \\
\hline 13.61 & 0.07 & $<$ & 0.50 \\
\hline 15.11 & & 0.07 & $<$ & 0.50 \\
\hline
\end{tabular}

\begin{tabular}{|r|c|c|c|c|}
\hline \multicolumn{5}{|c|}{ Run \#4 } \\
\hline \multicolumn{2}{|c|}{$0.5 \mathrm{M} \mathrm{HN}_{3}$, Staccato flow } \\
\hline $\begin{array}{c}\text { Eluent } \\
\text { volume } \\
(\mathrm{BV})\end{array}$ & $\begin{array}{c}{[\mathrm{Cs}]} \\
(\mathrm{mg} / \mathrm{L})\end{array}$ & $\begin{array}{c}{[\mathrm{K}]} \\
(\mathrm{mg} / \mathrm{L})\end{array}$ \\
\hline 2.51 & & 0.10 & & 15.3 \\
\hline 3.43 & & 3044 & & 155 \\
\hline 5.60 & & 2410 & & 11.1 \\
\hline 7.67 & & 2.95 & & 19.6 \\
\hline 9.85 & & 0.48 & & 13.7 \\
\hline 11.97 & & 0.19 & $<$ & 5.00 \\
\hline
\end{tabular}

\begin{tabular}{|c|c|c|}
\hline \multicolumn{3}{|c|}{ 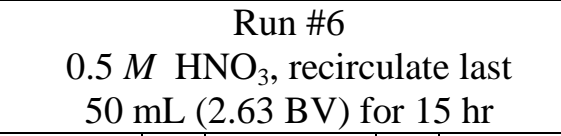 } \\
\hline $\begin{array}{c}\text { Eluent } \\
\text { volume } \\
\text { (BV) }\end{array}$ & $\begin{array}{c}{[\mathrm{Cs}]} \\
(\mathrm{mg} / \mathrm{L})\end{array}$ & $\begin{array}{c}{[\mathrm{K}]} \\
(\mathrm{mg} / \mathrm{L})\end{array}$ \\
\hline 1.01 & 0.04 & 18.2 \\
\hline 2.03 & 0.02 & 64.0 \\
\hline 3.03 & 0.02 & 37.6 \\
\hline 5.66 & 1520 & 80.2 \\
\hline
\end{tabular}

\begin{tabular}{|c|c|c|}
\hline \multicolumn{3}{|c|}{ Run \#5 } \\
Extended run, cesium loading \\
\hline $\begin{array}{c}\text { Surrogate } \\
\text { volume } \\
(\mathrm{BV})\end{array}$ & $\begin{array}{c}\text { Feed } \\
{[\mathrm{Cs}]} \\
(\mathrm{mg} / \mathrm{L})\end{array}$ & $\begin{array}{c}\text { Effluent } \\
{[\mathrm{Cs}]} \\
(\mathrm{mg} / \mathrm{L})\end{array}$ \\
\hline 30 & 26.0 & 0.11 \\
\hline 57 & 26.0 & 0.10 \\
\hline 87 & 26.0 & 0.24 \\
\hline 127 & 26.1 & 0.26 \\
\hline 175 & 26.1 & 0.15 \\
\hline 208 & 26.1 & 1.49 \\
\hline 220 & 26.4 & 4.59 \\
\hline 247 & 26.8 & 10.2 \\
\hline 290 & 28.4 & 20.4 \\
\hline 330 & 33.5 & 25.7 \\
\hline 372 & 38.3 & 28.8 \\
\hline 387 & 42.9 & 31.3 \\
\hline 426 & 44.4 & 33.3 \\
\hline 454 & 48.3 & 39.4 \\
\hline
\end{tabular}

\begin{tabular}{|r|c|c|c|c|}
\hline \multicolumn{5}{|c|}{ Run \#7 } \\
\hline \multicolumn{3}{|c|}{$0.5 M$ formic acid, $1 \mathrm{BV} / \mathrm{hr}$} \\
\hline $\begin{array}{c}\text { Eluent } \\
\text { volume } \\
(\mathrm{BV})\end{array}$ & & $\begin{array}{c}{[\mathrm{Cs}]} \\
(\mathrm{mg} / \mathrm{L})\end{array}$ & & $\begin{array}{c}{[\mathrm{K}]} \\
(\mathrm{mg} / \mathrm{L})\end{array}$ \\
\hline 1.32 & $<$ & 0.01 & & 16.8 \\
\hline 2.71 & $<$ & 0.01 & & 28.3 \\
\hline 4.16 & & 2520 & & 118 \\
\hline 5.53 & & 3640 & & 163 \\
\hline 6.94 & & 168 & & 10.0 \\
\hline 8.39 & & 22.4 & $<$ & 0.50 \\
\hline 9.85 & & 11.8 & $<$ & 0.50 \\
\hline 11.33 & & 6.61 & $<$ & 0.50 \\
\hline 12.86 & & 4.27 & & 2.22 \\
\hline 14.39 & & 2.76 & $<$ & 0.50 \\
\hline 15.93 & & 1.83 & $<$ & 0.50 \\
\hline 17.47 & & 1.29 & $<$ & 0.50 \\
\hline 18.94 & & 0.97 & $<$ & 0.50 \\
\hline 19.45 & & 0.81 & $<$ & 0.50 \\
\hline
\end{tabular}

B-2 


\begin{tabular}{|r|c|c|c|c|}
\hline \multicolumn{5}{|c|}{ Run \#8 } \\
\hline \multicolumn{2}{|c|}{$0.8 M$ boric acid, 1 BV/hr } \\
\hline $\begin{array}{c}\text { Eluent } \\
\text { volume } \\
(\mathrm{BV})\end{array}$ & & $\begin{array}{c}{[\mathrm{Cs}]} \\
(\mathrm{mg} / \mathrm{L})\end{array}$ & $\begin{array}{c}{[\mathrm{K}]} \\
(\mathrm{m} / \mathrm{L})\end{array}$ \\
\hline 1.16 & $<$ & 0.01 & & 18.4 \\
\hline 2.42 & $<$ & 0.01 & & 30.7 \\
\hline 3.73 & $<$ & 0.01 & & 84.8 \\
\hline 5.02 & $<$ & 0.01 & & 74.4 \\
\hline 6.35 & $<$ & 0.01 & & 44.4 \\
\hline 7.70 & $<$ & 0.01 & & 22.0 \\
\hline 9.08 & & 124 & & 28.1 \\
\hline 10.47 & & 444 & & 19.8 \\
\hline 11.89 & & 629 & & 6.55 \\
\hline 13.26 & & 645 & & 8.70 \\
\hline 14.69 & & 586 & & 8.34 \\
\hline 16.10 & & 502 & & 28.0 \\
\hline 17.47 & & 419 & & 2.11 \\
\hline 18.02 & & 372 & $<$ & 0.50 \\
\hline
\end{tabular}

\begin{tabular}{|r|r|r|r|r|}
\hline \multicolumn{5}{|c|}{ Run \#10 } \\
\hline $\begin{array}{c}\text { Eluent } \\
\text { volume } \\
(\mathrm{BV})\end{array}$ & & $\begin{array}{c}\text { [Cs] } \\
(\mathrm{mg} / \mathrm{L})\end{array}$ & & $\begin{array}{c}{[\mathrm{K}]} \\
(\mathrm{mg} / \mathrm{L})\end{array}$ \\
\hline 1.31 & $<$ & 0.10 & & 9.09 \\
\hline 2.59 & $<$ & 0.10 & & 14.2 \\
\hline 3.88 & $<$ & 0.10 & & 9.09 \\
\hline 5.10 & $<$ & 0.10 & & 9.82 \\
\hline 6.37 & & 0.15 & & 11.6 \\
\hline 7.67 & & 0.14 & & 9.78 \\
\hline 8.97 & & 0.12 & & 9.63 \\
\hline 10.33 & & 247 & & 22.2 \\
\hline 11.74 & & 2880 & & 89.1 \\
\hline 13.12 & & 904 & & 48.5 \\
\hline 14.44 & & 4.22 & $<$ & 5.00 \\
\hline 15.72 & & 0.91 & $<$ & 5.00 \\
\hline 17.06 & & 0.49 & $<$ & 5.00 \\
\hline \multicolumn{5}{|c|}{} \\
\hline
\end{tabular}

\begin{tabular}{|c|c|c|c|}
\hline \multicolumn{4}{|c|}{$\begin{array}{c}\text { Run \#9 } \\
0.2 \mathrm{MNO}_{3}, 1 \mathrm{BV} / \mathrm{hr}\end{array}$} \\
\hline $\begin{array}{c}\text { Eluent } \\
\text { volume } \\
(\mathrm{BV})\end{array}$ & $\begin{array}{c}{[\mathrm{Cs}]} \\
(\mathrm{mg} / \mathrm{L})\end{array}$ & & $\begin{array}{c}{[\mathrm{K}]} \\
(\mathrm{mg} / \mathrm{L})\end{array}$ \\
\hline 1.18 & 0.11 & & 5.18 \\
\hline 2.36 & 0.11 & & 16.4 \\
\hline 3.46 & 0.12 & & 20.0 \\
\hline 4.55 & 0.20 & & 16.4 \\
\hline 5.72 & 1990 & & 63.6 \\
\hline 6.88 & 4480 & & 162. \\
\hline 8.07 & 181 & & 23.6 \\
\hline 9.26 & 2.60 & & 12.7 \\
\hline 10.44 & 1.28 & $<$ & 5.00 \\
\hline 11.67 & 0.71 & $<$ & 5.00 \\
\hline 12.92 & 0.43 & & 12.7 \\
\hline 14.15 & 0.31 & $<$ & 5.00 \\
\hline 15.41 & 0.24 & $<$ & 5.00 \\
\hline 16.17 & 0.21 & $<$ & 5.00 \\
\hline
\end{tabular}

\begin{tabular}{|r|r|r|r|r|}
\hline \multicolumn{5}{|c|}{ Run \#11 } \\
\hline \multicolumn{2}{|c|}{$0.5 \mathrm{MNO}, 0.56 \mathrm{BV} / \mathrm{hr}$} \\
\hline $\begin{array}{c}\text { Eluent } \\
\text { volume } \\
(\mathrm{BV})\end{array}$ & $\begin{array}{c}\text { [Cs] } \\
(\mathrm{mg} / \mathrm{L})\end{array}$ & $\begin{array}{c}\text { [K] } \\
(\mathrm{mg} / \mathrm{L})\end{array}$ \\
\hline 0.76 & 0.14 & & 14.6 \\
\hline 1.49 & 0.14 & & 25.2 \\
\hline 2.20 & 0.13 & & 37.7 \\
\hline 2.98 & & 0.13 & & 52.6 \\
\hline 3.81 & & 4280 & & 181 \\
\hline 4.66 & & 6080 & & 345 \\
\hline 5.49 & & 22.5 & $<$ & 5.00 \\
\hline 6.38 & & 3.88 & $<$ & 5.00 \\
\hline 7.32 & & 1.96 & $<$ & 5.00 \\
\hline 8.20 & & 1.39 & & 10.90 \\
\hline 9.04 & & 0.82 & $<$ & 5.00 \\
\hline 9.90 & & 0.58 & $<$ & 5.00 \\
\hline 10.85 & & 0.43 & & 20.50 \\
\hline
\end{tabular}




\begin{tabular}{|r|r|r|r|r|}
\hline \multicolumn{5}{|c|}{ Run \#12 } \\
\hline $\begin{array}{c}\text { Eluent } \\
\text { volume } \\
(\mathrm{BV})\end{array}$ & $\begin{array}{c}\text { [Cs] } \\
(\mathrm{mg} / \mathrm{L})\end{array}$ & & $\begin{array}{c}{[\mathrm{K}]} \\
(\mathrm{mg} / \mathrm{L})\end{array}$ \\
\hline 1.23 & & 0.14 & & 24.2 \\
\hline 2.49 & & 0.14 & & 29.4 \\
\hline 3.71 & & 3790 & & 180 \\
\hline 4.89 & & 1640 & & 95.0 \\
\hline 6.04 & & 4.08 & $<$ & 5.00 \\
\hline 7.21 & & 1.47 & $<$ & 5.00 \\
\hline 8.44 & & 0.76 & $<$ & 5.00 \\
\hline 9.66 & & 0.48 & $<$ & 5.00 \\
\hline 10.86 & & 0.34 & $<$ & 5.00 \\
\hline 12.09 & 0.25 & $<$ & 5.00 \\
\hline 13.34 & & 0.21 & $<$ & 5.00 \\
\hline 14.59 & & 0.20 & $<$ & 5.00 \\
\hline 15.82 & & 0.17 & & 15.30 \\
\hline
\end{tabular}

\begin{tabular}{|c|c|c|c|c|}
\hline \multicolumn{5}{|c|}{ Run \#14 } \\
$0.5 \mathrm{M} \mathrm{HNO}_{3}$, recirculate last \\
$50 \mathrm{~mL}(2.33 \mathrm{BV})$ for $15 \mathrm{hr}$ \\
\hline $\begin{array}{c}\text { Eluent } \\
\text { volume } \\
(\mathrm{BV})\end{array}$ & & $\begin{array}{c}{[\mathrm{Cs}]} \\
(\mathrm{mg} / \mathrm{L})\end{array}$ & & $\begin{array}{c}{[\mathrm{K}]} \\
(\mathrm{mg} / \mathrm{L})\end{array}$ \\
\hline 1.15 & $<$ & 0.01 & & 12.9 \\
\hline 2.34 & & 0.10 & & 31.9 \\
\hline 3.51 & & 4700 & & 186 \\
\hline 4.73 & & 1820 & & 82.2 \\
\hline 7.06 & & 1.23 & $<$ & 5.00 \\
\hline
\end{tabular}

\begin{tabular}{|c|c|c|c|}
\hline \multicolumn{4}{|c|}{$\begin{array}{c}\text { Run \#13 } \\
0.5 \text { then } 0.05 M \mathrm{HNO}_{3}, 1 \mathrm{BV} / \mathrm{hr}\end{array}$} \\
\hline $\begin{array}{c}\text { Eluent } \\
\text { volume } \\
\text { (BV) }\end{array}$ & $\begin{array}{c}{[\mathrm{Cs}]} \\
(\mathrm{mg} / \mathrm{L})\end{array}$ & & $\begin{array}{c}{[\mathrm{K}]} \\
(\mathrm{mg} / \mathrm{L})\end{array}$ \\
\hline 1.21 & 0.13 & & 16.2 \\
\hline 2.46 & 0.13 & & 12.9 \\
\hline 3.71 & 4490 & & 174 \\
\hline 4.96 & 1970 & & 74.3 \\
\hline 6.20 & 2.39 & $<$ & 5.00 \\
\hline 7.52 & 1.35 & $<$ & 5.00 \\
\hline 8.86 & 0.99 & $<$ & 5.00 \\
\hline 10.09 & 0.80 & $<$ & 5.00 \\
\hline 11.36 & 0.51 & $<$ & 5.00 \\
\hline 12.63 & 0.33 & $<$ & 5.00 \\
\hline 13.85 & 0.23 & $<$ & 5.00 \\
\hline 15.09 & 0.18 & $<$ & 5.00 \\
\hline 16.32 & 0.16 & $<$ & 5.00 \\
\hline
\end{tabular}

\begin{tabular}{|r|c|c|c|c|}
\hline \multicolumn{5}{|c|}{ Run \#15 } \\
\hline $\begin{array}{c}\text { Eluent } \\
\text { volume } \\
(\mathrm{BV})\end{array}$ & $\begin{array}{c}\text { [Cs] } \\
(\mathrm{mg} / \mathrm{L})\end{array}$ & & $\begin{array}{c}{[\mathrm{K}]} \\
(\mathrm{mg} / \mathrm{L})\end{array}$ \\
\hline 1.21 & 0.01 & & 13.00 \\
\hline 2.50 & & 0.03 & & 33.70 \\
\hline 3.78 & & 6950 & & 244.00 \\
\hline 5.04 & & 131 & & 9.57 \\
\hline 6.26 & & 1.12 & $<$ & 0.50 \\
\hline 7.53 & & 0.38 & & 2.08 \\
\hline 8.82 & & 0.25 & $<$ & 0.50 \\
\hline 10.13 & & 0.17 & $<$ & 0.50 \\
\hline 11.40 & & 0.13 & $<$ & 0.50 \\
\hline 12.69 & & 0.11 & $<$ & 0.50 \\
\hline 13.95 & & 0.08 & $<$ & 0.50 \\
\hline 15.16 & & 0.07 & $<$ & 0.50 \\
\hline
\end{tabular}

\begin{tabular}{|r|c|c|c|c|}
\hline \multicolumn{5}{|c|}{ Run \#16 } \\
\hline \multicolumn{2}{|c|}{0.5 then $0.05 \mathrm{HNO}_{3}, 1 \mathrm{BV} / \mathrm{hr}$} \\
\hline $\begin{array}{c}\text { Eluent } \\
\text { volume } \\
(\mathrm{BV})\end{array}$ & $\begin{array}{c}{[\mathrm{Cs}]} \\
(\mathrm{mg} / \mathrm{L})\end{array}$ & $\begin{array}{c} \\
{[\mathrm{K}]} \\
(\mathrm{mg} / \mathrm{L})\end{array}$ \\
\hline 1.59 & 0.01 & & 15.6 \\
\hline 3.02 & $<$ & 0.01 & & 35.5 \\
\hline 4.45 & & 4460 & & 171 \\
\hline 5.95 & & 2.32 & $<$ & 0.50 \\
\hline 7.35 & & 0.26 & $<$ & 0.50 \\
\hline 8.72 & & 0.19 & $<$ & 0.50 \\
\hline 10.10 & & 0.17 & $<$ & 0.50 \\
\hline 11.41 & & 0.12 & $<$ & 0.50 \\
\hline 12.68 & & 0.11 & $<$ & 0.50 \\
\hline 13.98 & & 0.09 & $<$ & 0.50 \\
\hline 15.26 & & 0.08 & & 1.65 \\
\hline 16.13 & & 0.07 & $<$ & 0.50 \\
\hline
\end{tabular}




\begin{tabular}{|r|c|c|c|c|}
\hline \multicolumn{5}{|c|}{ Run \#17 } \\
\hline $\begin{array}{c}|c| \\
0.5 \\
\text { Eluent } \\
\text { volume } \\
(\mathrm{BV})\end{array}$ & $\begin{array}{c}{[\mathrm{Cs}]} \\
(\mathrm{mg} / \mathrm{L})\end{array}$ & $\begin{array}{c}{[\mathrm{K}]} \\
(\mathrm{mg} / \mathrm{L})\end{array}$ \\
\hline 1.31 & $<$ & 0.01 & & 10.5 \\
\hline 2.61 & $<$ & 0.01 & & 24.2 \\
\hline 3.94 & & 6380 & & 222 \\
\hline 5.41 & & 319 & & 12.2 \\
\hline 6.89 & & 36.9 & $<$ & 0.50 \\
\hline 8.33 & & 19.5 & $<$ & 0.50 \\
\hline 9.75 & & 11.8 & $<$ & 0.50 \\
\hline 11.19 & & 7.25 & $<$ & 0.50 \\
\hline 12.55 & & 5.35 & & 0.57 \\
\hline 13.94 & & 3.42 & & 0.87 \\
\hline 15.28 & & 2.64 & $<$ & 0.50 \\
\hline 16.22 & & 1.99 & & 0.49 \\
\hline
\end{tabular}

\begin{tabular}{|c|c|}
\hline \multicolumn{2}{|c|}{$\begin{array}{c}\text { Cesium concentrations in } \\
\text { composite surrogate effluent } \\
\text { samples during cesium loading } \\
\text { cycles. Data for Runs \#1, 2, and 5 } \\
\text { are provided in the tables above. }\end{array}$} \\
\hline Run \# & {$[\mathrm{Cs}$ (mg/L) } \\
\hline 3 & 0.04 \\
\hline 4 & 0.12 \\
\hline 6 & 0.13 \\
\hline 7 & 0.25 \\
\hline 8 & 0.14 \\
\hline 9 & 0.10 \\
\hline 10 & 0.19 \\
\hline 11 & 0.17 \\
\hline 12 & 0.17 \\
\hline 13 & 0.19 \\
\hline 14 & 0.33 \\
\hline 15 & 0.30 \\
\hline 16 & 0.05 \\
\hline 17 & 0.34 \\
\hline
\end{tabular}





\section{Appendix C VOLATILES ANALYSIS DETECTION LIMITS}

Volatile Organic Compounds by EPA Method 8260B_-Detection Limits

Analyte

Acetone

Benzene

Bromobenzene

Bromochloromethane

Bromodichloromethane

Bromoform

Bromomethane

2-Butanone

sec-Butylbenzene

n-Butylbenzene

tert-Butylbenzene

Carbon disulfide

Carbon Tetrachloride

Chlorobenzene

Chlorodibromomethane

Chloroethane

Chloroform

Chloromethane

2-Chlorotoluene

4-Chlorotoluene

1,2-Dibromo-3-chloropropane

1,2-Dibromoethane (EDB)

Dibromomethane

1,4-Dichlorobenzene

1,3-Dichlorobenzene

1,2-Dichlorobenzene

Dichlorodifluoromethane

1,1-Dichloroethane

1,2-Dichloroethane

cis-1,2-Dichloroethene

1,1-Dichloroethene

trans-1,2-Dichloroethene

1,3-Dichloropropane

1,2-Dichloropropane

2,2-Dichloropropane

cis-1,3-Dichloropropene

trans-1,3-Dichloropropene

1,1-Dichloropropene

Ethylbenzene

Hexachlorobutadiene
Detection Limit $(\mu \mathrm{g} / \mathrm{L})$

50.0

1.0

1.0

1.0

1.0

1.0

1.0

50.0

1.0

1.0

1.0

1.0

1.0

1.0

1.0

1.0

1.0

1.0

1.0

1.0

5.0

1.0

1.0

1.0

1.0

1.0

1.0

1.0

1.0

1.0

1.0

1.0

1.0

1.0

1.0

1.0

1.0

1.0

1.0

1.0 
2-Hexanone

50.0

Isopropylbenzene

p-Isopropyltoluene

1.0

Methyl tert-Butyl Ether

1.0

Methylene Chloride

5.0

4-Methyl-2-pentanone

10.0

Naphthalene

5.0

n-Propylbenzene

1.0

Styrene

1.0

1,1,1,2-Tetrachloroethane

1.0

1,1,2,2-Tetrachloroethane

1.0

Tetrachloroethene

1.0

Toluene

1.0

1,2,3-Trichlorobenzene

1.0

1,2,4-Trichlorobenzene

1.0

1,1,2-Trichloroethane

1.0

1,1,1-Trichloroethane

1.0

Trichloroethene

1.0

Trichlorofluoromethane

1.0

1,2,3-Trichloropropane

1.0

1,3,5-Trimethylbenzene

1.0

1,2,4-Trimethylbenzene

1.0

Vinyl chloride

1.0

Xylenes, total

1.0 


\section{INTERNAL DISTRIBUTION}
1. J. F. Birdwell, Jr.
4. B. E Lewis, Jr.
2. E. D. Collins
5. P. A. Taylor
3. R. D. Hunt
6. ORNL Laboratory Records-RC

\section{EXTERNAL DISTRIBUTION}

7. H. Lauren Johnson-The University of Tennessee

8. William King-SRNL

9. Dan McCabe-SRNL

10. Chet Miller-DOE

11. Tim Punch-SRS

12. Renee Spires-SRS

13. Patricia Suggs-DOE

14. Murray Thorson-Bechtel, Hanford

15. Bill Wilmarth-SRNL 